\title{
Optical investigation of fuel and in-cylinder air-swirl effects in a high-speed direct-injection engine
}

International J of Engine Research 2015, Vol. 16(6) 716-737 (C) IMechE 2014

Reprints and permissions: sagepub.co.uk/journalsPermissions.nav DOI: $10.1177 / 1468087414546503$ jer.sagepub.com

(SAGE

\author{
Thomas Hülser', Markus Jakob², Gerd Grünefeld', Philipp Adomeit ${ }^{3}$, \\ Stefan Pischinger ${ }^{2}$ and Daniel Klein ${ }^{2}$
}

\begin{abstract}
The primary aim of this study is to investigate current issues of combustion in high-speed direct-injection diesel engines in detail by optical diagnostics. Both fuel and engine design are considered. Recently, measurements of engine-out emissions demonstrated that approximately soot-free combustion can be achieved using a newly designed two-component fuel named BLT. It was composed of $70 \%$ butyl levulinate and $30 \% \mathrm{n}$-tetradecane (by volume). In this work, the underlying mechanism is clarified by in-cylinder visualization of $\mathrm{OH}^{*}$ radicals and soot. In particular, it turns out that in-cylinder soot formation is avoided almost completely, that is, the soot oxidation process is much less important. This is basically achieved by both the oxygen content (about 21\%) and the low cetane number (approximately 33) of BLT. The latter leads to enhanced pre-mixing of fuel and air. Consequently, soot formation can be greatly reduced because it depends on the air-fuel ratio of the mixture shortly before high-temperature combustion. The influence of in-cylinder air swirl on combustion and soot formation is also studied for both BLT and conventional diesel fuel, respectively, using the same optical diagnostic. The measurements show that the combustion zone strongly depends on the local gas-flow velocity for diesel fuel. Soot formation decreases with increasing swirl because of enhanced air entrainment and pre-mixing of fuel and air. In addition, the results indicate that soot oxidation is improved under high-swirl conditions for diesel fuel. In contrast, the influence of swirl on the combustion of BLT is overall found to be weak, suggesting that swirl could be reduced in future high-speed direct-injection engines for BLT-like fuels.
\end{abstract}

\section{Keywords}

High-speed direct-injection engine, high-speed visualization, soot luminosity, $\mathrm{OH}^{*}$ chemiluminescence, alternative fuels

Date received: 21 May 2012; accepted: 2 July 2014

\section{Introduction}

It was demonstrated recently that combustion in highspeed direct-injection (HSDI) diesel engines can be improved using a tailor-made two-component fuel instead of conventional diesel fuel. ${ }^{1}$ The new blend was composed of $70 \%$ butyl levulinate and $30 \%$ ntetradecane (by volume). Thus, it was named BLT. Interestingly, butyl levulinate is a cellulose-derived biofuel. However, due to its insufficient auto-ignition ability, n-tetradecane was added. The latter has a high auto-ignition ability, which is characterized by a cetane number $(\mathrm{CN})$ of 95 . According to Janssen et al. ${ }^{1}$ the volume fraction of $30 \%$ n-tetradecane allows autoignition of BLT in the engine under all operating conditions investigated therein. The corresponding $\mathrm{CN}$ of BLT is about 33. The fraction of n-tetradecane is not further increased, basically for two reasons. First, it should be noted that butyl levulinate is an oxygenated fuel compound, in contrast to n-tetradecane. It was demonstrated previously that the soot emissions of diesel engines decrease approximately linearly with increasing mass fraction of fuel-bound oxygen (Mueller et al. ${ }^{2}$ and references therein). Thus, the fraction of the oxygenated component should be as high as possible.

\footnotetext{
'Institute for Laser Diagnostics in Thermo-Fluid Dynamics, RWTH Aachen University, Aachen, Germany

${ }^{2}$ Institute for Combustion Engines, RWTH Aachen University, Aachen, Germany

${ }^{3}$ FEV GmbH, Aachen, Germany
}

\section{Corresponding author:}

Thomas Hülser, Institute for Laser Diagnostics in Thermo-Fluid Dynamics, RWTH Aachen University, Schinkelstr. 8, D-52062 Aachen, Germany.

Email: huelser@|tfd.rwth-aachen.de 
Furthermore, the resulting $\mathrm{CN}$ of the blend should be relatively low because previous research also indicated that the soot emissions decrease generally with decreasing $\mathrm{CN}$, at least for light-duty vehicles. ${ }^{3,4}$ In fact, it turned out that approximately soot-free diesel combustion could be achieved using BLT in the whole range of operating conditions, according to the New European Driving Cycle (NEDC). ${ }^{1}$ However, the relative importance of the $\mathrm{CN}$ and the oxygen content for soot reduction cannot be exactly quantified by now. According to Mueller et al. ${ }^{2}$ and the references therein, fuel-bound oxygen is likely more effective for soot reduction than the oxygen of the ambient air, which is entrained into the spray. The latter mechanism is promoted by a low CN. However, the air entrainment cannot be quantified due to the highly dynamic combustion process in HSDI engines. ${ }^{4,5}$ The relative importance of soot formation and oxidation processes is also still under scientific debate (Jakob et al. ${ }^{5}$ and references therein).

BLT was also characterized in terms of all other regulated emissions and efficiency in Janssen et al. ${ }^{1}$ Overall, the results were very promising. Thus, it is a major aim of this study to investigate the combustion of BLT in more detail by optical in-cylinder diagnostics under approximately realistic operating conditions, that is, in an optically accessible HSDI engine, which is very similar to the all-metal engine employed in Janssen et al. ${ }^{1}$ The differences of both engines are discussed in section "Engines and operating conditions." The used part-load operating conditions $\left(1500 \mathrm{~min}^{-1}\right.$ and 6.8 bar indicated mean effective pressure (IMEP)) and variations in fuel and in-cylinder air swirl are also discussed in section "Engines and operating conditions." In particular, the soot reduction mechanism is studied. In this way, the fuel and engine design process, which is described in more detail in Janssen et al. ${ }^{1,6}$ is supported. This research has been conducted in order to develop a new combustion system, which is operated on crude-oil independent, carbon-neutral, liquid fuel. The chemical composition and production of butyl levulinate $\left(\mathrm{C}_{9} \mathrm{H}_{16} \mathrm{O}_{3}\right)$ are described in Janssen et al. ${ }^{1}$ and the references therein. Butyl levulinate belongs to the group of levulinic esters, which can be produced from levulinic acid by dehydration/hydrogenation or esterification, while levulinic acid is derived from cellulose by acid hydrolysis. New biofuels produced from cellulose, lignins, and others may also be available in the future because new production routes are currently being developed based on microbial reactors synthesis of hydrocarbons by bacteria, yeasts, and fungi. ${ }^{7}$

Previous optical investigations in constant-volume vessels $^{4,8,9}$ and engines ${ }^{5,10,11}$ indicated that soot formation in lifted diesel flames depends on the stoichiometric ratio, $\lambda$, of the mixture shortly before hightemperature combustion, that is, close to the lift-off position. Soot formation can be completely avoided by providing a $\lambda$ larger than 0.5 there (corresponding to an equivalence ratio, $\phi$, of 2). ${ }^{8,11}$ This can be achieved either by fuel-bound oxygen or by pre-mixing of fuel and air. ${ }^{2}$ Accordingly, the engine-out soot emissions of HSDI engines generally depend on $\mathrm{CN}$, as noted previously, because increasing $\mathrm{CN}$ generally leads to both decreasing ignition delay and decreasing flame lift-off length (LOL). 4,12,13 Consequently, the stoichiometric ratio at the lift-off location decreases because less time and space are available for fuel-air pre-mixing.

However, the influence of $\mathrm{CN}$ on the LOL may be offset by other effects in real engines, for example, jetjet or jet-wall interaction. ${ }^{14,15}$ Furthermore, laser-based $\lambda$ measurements at the assumed position of flame liftoff in an engine demonstrated that $\lambda$ did not determine the engine-out soot emissions, indicating that the latter were rather dominated by the soot oxidation process. ${ }^{16}$ Overall, the importance of the stoichiometric ratio at the LOL is generally not clear. Thus, it is considered in this article.

The current optical engine and the all-metal engine employed in Janssen et al. ${ }^{1}$ are equipped with a recently developed port concept, ${ }^{17}$ in order to optimize the gas exchange process. It is described in more detail in section "Experimental setup." In particular, the influence of the inhomogeneity of the in-cylinder air flow on combustion is studied in this work because it was demonstrated previously that there may be a strong link between local flow velocity and soot formation. ${ }^{18}$ Unfortunately, little is known about the underlying mechanism. Thus, it is investigated by combustion and flow visualization in this work.

Optical in-cylinder diagnostics were applied to operating diesel engines before, $2,10,14,16,17,19-22$ but most of the work in this field focused on heavy-duty engines. It should be noted that combustion in HSDI, that is, light-duty diesel engine, and heavy-duty diesel engine is substantially different. ${ }^{3,5}$ For instance, the in-cylinder air swirl is typically stronger in HSDI engines as compared to heavy-duty engines. ${ }^{23,24}$ It is demonstrated in this article that there is indeed a strong influence of air swirl on combustion and soot formation in the investigated engine for high-swirl operating conditions. It turns out that previously developed conceptual models of diesel combustion ${ }^{10,11,25-29}$ are not exactly applicable to these conditions because they neglect the influence of air swirl.

The influence of air swirl on combustion in HSDI engines was previously investigated by in-cylinder imaging techniques in Adolph et al. ${ }^{17}$ Adomeit et al. ${ }^{18}$ Taschek et al. ${ }^{21}$ Miles, ${ }^{23}$ and Koyanagi et al. ${ }^{24}$ The findings and conclusions of these studies are compared to the present observations in section "Results and discussion." The combustion of alternative fuels, namely, n-heptane, n-decane, and 1-decanol, was previously explored in the same HSDI engine and by the same optical setup as in this work. ${ }^{5}$ To the authors' knowledge, the combustion of a tailored two-component fuel in an HSDI engine was not visualized before by incylinder imaging techniques.

In this work, second-stage ignition and subsequent, near-stoichiometric combustion are visualized by $\mathrm{OH}^{*}$ 
chemiluminescence imaging. ${ }^{30}$ In principle, the same approach was previously applied to diesel combustion in engines $2,14,16,20,21$ and constant-volume vessels. 4,9,12,13,31 In addition, soot luminosity images are acquired simultaneously in this experiment. Thereby, fuel-rich combustion zones are visualized. ${ }^{25}$ However, only sufficiently hot soot is observed due to the strong temperature dependence of the luminosity. ${ }^{19,32}$ The acquired $\mathrm{OH}^{*}$ images also yield information on the overlap between the liquid fuel distribution and hightemperature combustion, as discussed in more detail in Jakob et al. ${ }^{5}$

The influence of swirl was investigated previously by both $\mathrm{OH}^{*}$ and soot luminosity imaging in an HSDI engine. ${ }^{21}$ However, these earlier measurements were conducted with split injection, in contrast to this study. It should be noted that a strong influence of the pilot injection on ignition and combustion of the main injection is often found, ${ }^{24,33}$ in particular if the latter is triggered by the combusting pilot injection. ${ }^{21,34}$ Consequently, the structure of diesel flames is found to be significantly different in this study, as compared to the corresponding results in Taschek et al. ${ }^{21}$

\section{Experimental setup}

\section{Engines and operating conditions}

In this study, an optically accessible HSDI engine and a corresponding all-metal engine are employed. ("HSDI" engines can be operated at relatively high speed.) Both engines are identical concerning the injection system (i.e. fuel pump, fuel rail, and injector), and they are also approximately equal with regard to combustion chamber geometry. In Table 1, the corresponding data are shown. Further information about the single-cylinder engines is available in Jakob et al. ${ }^{5}$ and Müther et al. ${ }^{35}$

A sketch of the experimental setup for the optical engine and the shapes of the optical and all-metal piston bowls are given in Figure 1. The optical engine is equipped with an elongated piston and $\omega$-shaped quartz glass piston bowl. The curvature of the central bowl surface of the optical engine is reduced as compared to the all-metal engine, in order to avoid strong optical distortion of the images. ${ }^{5}$ However, the pistoncrown window still causes spherical image distortion. Therefore, additional image post-processing steps are necessary, as described in section "Optical setup." Note also that the in-cylinder phenomena in the swirl plane are visualized via a fixed mirror in the clearance of the elongated piston.

In order to avoid contact between the piston rings and the inner surface of the window cassettes, which are replaced by metal dummies for this experiment, the fire land height is increased. According to Aronsson et al. $^{36}$ the resulting effect on combustion and in particular unburnt hydrocarbon (HC) emissions is weak for HSDI engines with combustion in the piston bowl and
Table I. Specifications of the all-metal and optical singlecylinder engine.

\begin{tabular}{lll}
\hline & Unit & Single-cylinder engines \\
\hline Single-cylinder swept volume & $\mathrm{cm}^{3}$ & 390 \\
Stroke & $\mathrm{mm}$ & 88.3 \\
Bore diameter & $\mathrm{mm}$ & 75 \\
Compression ratio & - & I5 (simulated for \\
& & optical engine) \\
Valves per cylinder & - & 4 \\
Fuel injection system & - & Bosch Piezo Common \\
& & Rail System \\
Injector & - & Bosch CRI 3.3 \\
Number of nozzle holes & - & 8 \\
Included angle of fuel jets & $\circ$ & 153 \\
Nozzle hole diameter & $\mu \mathrm{m}$ & 109 \\
\hline
\end{tabular}

injection close to top dead center (TDC) of combustion.

The port concept of both engines is described in Adolph et al. ${ }^{17}$ It was designed to achieve high flow rate at moderate air-swirl intensity. A parallel arrangement of the valves is employed, allowing high flow rates and a central, vertical injector position. Accordingly, each engine has one tangential and one straight (filling) intake port. Both intake valves have seat swirl chamfers in order to gain high swirl intensity for low valve lift. However, the valve lift is relatively large $(8 \mathrm{~mm})$ in this study, and the swirl intensity is enhanced by complete deactivation of the filling port because this is a widely used method. ${ }^{17}$

The optical diesel engine is fired for a limited number of successive cycles, before soot deposits impair the quality of optical diagnostics substantially. (The cycle numbers are given in section "Optical setup.") Due to this limitation, all operating conditions like engine lubricant temperatures, engine speed, intake temperature, and pressure have to be adjusted prior to the first fired cycle. The cooling-water and oil temperature are conditioned to $90{ }^{\circ} \mathrm{C}$. Note that skip firing is not used.

Since the limited number of fired cycles of the optical diesel engine is insufficient to enable a controlled external exhaust gas recirculation (EGR), a second engine operating on diesel fuel is used to provide external EGR. The exhaust gas of this engine is mixed with the intake air of the optical engine before entering the supercharger. The concentration of $\mathrm{CO}_{2}$ in the intake is used as a measure of the inert gas concentration.

The close comparability of the all-metal and optical diesel engines allows the adaption of thermodynamically optimized operating parameters to the optical engine. In this study, the optical and all-metal research engines are operated at $1500 \mathrm{r} / \mathrm{min}^{-1}$, 6.8 bar IMEP, and equal $\mathrm{CO}_{2}$ concentration in the intake, as described below. Both engines are operated on BLT and conventional diesel fuel (EN 590) in consecutive experiments. Relevant fuel and injection parameters are given in Table 2. Note that the start of injection depends on the 


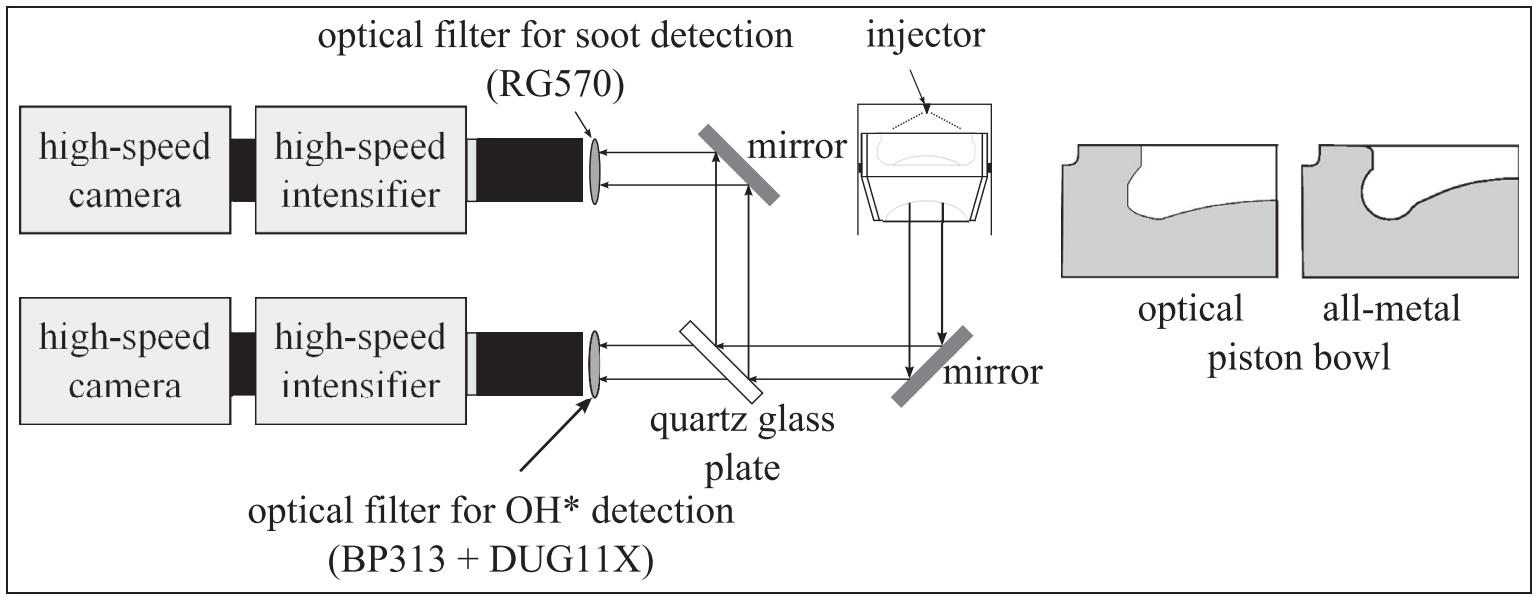

Figure I. Optical diesel engine setup and piston bowl shape of the all-metal engine. Note that the bowl of the optical engine is shown in Figure 5.

Table 2. Fuel properties and operating conditions at $1500 \mathrm{~min}^{-1}, 6.8 \mathrm{bar}$ IMEP.

\begin{tabular}{llll}
\hline & Unit & Diesel fuel & BLT \\
\hline Heating value & $\mathrm{MJ} / \mathrm{kg}$ & 42.9 & 32.8 \\
Oxygen content & $\mathrm{m}-\%$ & 0.14 & 14.6 \\
Cetane number & - & 53 & 33 \\
Boiling temperature & ${ }^{\circ} \mathrm{C}$ & $180-350$ & $232-252$ \\
Viscosity & $\mathrm{mm}^{2} / \mathrm{s}$ & 3.6 & 2 \\
Fuel rail pressure & $\mathrm{bar}$ & 905 & 905 \\
Start of injection & ${ }^{\circ} \mathrm{CA}$ ATDC & -5.7 & -11.5 \\
"Energizing time of the injector" & $\mu \mathrm{s}$ (optical engine) & $415(415)$ & $520(523)$ \\
Stoichiometric air-fuel ratio & $\mu \mathrm{s}$ (all-metal engine) & 408 & 516 \\
Intake pressure (optical engine) & - & 1.69 & 1.66 \\
Intake temperature & bar & 2.4 & 2.4 \\
EGR rate & ${ }^{\circ} \mathrm{C}$ & 95 & 95 \\
\hline
\end{tabular}

BLT: 70\% butyl levulinate and 30\% n-tetradecane (by volume); CA: crank angle; ATDC: after top dead center; EGR: exhaust gas recirculation; PD: port deactivation."Energizing time of the injector" in the eighth row is given for the optical engine with and without PD (the latter in brackets), whereas it is only shown without PD for the all-metal engine in the ninth row.

investigated fuels, in order to compensate for differences of the ignition delay and early combustion behavior up to the center of combustion (mass fraction burnt of $50 \%$ (MFB50)), that is, the degree crank angle (CA) where $50 \%$ of the injected fuel mass has been converted. A detailed description of the injection timing procedure is given in Müther et al. ${ }^{35}$ Identical fuel rail pressure and start of injection timings are used for both engines. However, the injection timing depends on the fuel type. It is determined at a limited $\mathrm{NO}_{X}$ level of $0.5 \mathrm{~g} / \mathrm{kW} \mathrm{h}$ and a constant MFB50 for the all-metal engine. It was demonstrated previously that the allmetal engine is adjusted for maximum efficiency in this way. $^{35}$

The external EGR is increased for BLT ( $41 \%$, corresponding to $3.6 \% \mathrm{CO}_{2}$ and $17.1 \% \mathrm{O}_{2}$ in the intake) as compared to diesel fuel $\left(38 \%, 3 \% \mathrm{CO}_{2}, 17.4 \% \mathrm{O}_{2}\right)$, in order to achieve stationary $\mathrm{NO}_{X}$ emissions of $100 \mathrm{ppm}$ for both fuels at the all-metal engine. Increased $\mathrm{NO}_{X}$ emissions of BLT at equal EGR are likely caused by enhanced pre-mixed burn heat release, which is demonstrated in section "Results and discussion" (Kook and Pickett ${ }^{37}$ and references therein).

Table 2 also shows that the injection duration (in terms of the actuation time of the injector) is slightly different for both engines, in order to achieve comparable engine operation in terms of IMEP. (Note that there is a delay of about $0.5 \mathrm{~ms}$ between the end of the actuation time of the injector and complete needle closing, which is inferred from Mie scatter images.) The fuel injection is prolonged very slightly for BLT, as shown in Table 2, in order to achieve the same IMEP, when the engine is operated with port deactivation (PD).

The compression ratio of the optical engine is about 13.5, whereas the one of the all-metal engine is 15 . The decreased compression ratio of the optical engine is a common consequence of modifications for optical access. Differences between optical and corresponding 
all-metal HSDI engines are discussed in detail in Aronsson et al. ${ }^{36}$ Colban et al. ${ }^{38}$ Kashdan and Thirouard $^{39}$ and the references therein. It was concluded that modifications for optical access affect combustion and emissions, but this can be approximately compensated for by adjusting operating parameters such as intake temperature and/or pressure. A similar strategy is applied in this work. The boost pressure of the optical engine is increased by approximately 0.9 bar in order to reach the same pressure near TDC, that is, at injection timing (for both fuels and swirl intensities). (Note that this consequently slightly increases the intake air flow rate.) In addition, the intake temperature is increased by approximately $55 \mathrm{~K}$, so that the incylinder pressure rise in the range from $0{ }^{\circ} \mathrm{CA}$ to $5^{\circ} \mathrm{CA}$ is approximately equal for both engines (for both fuel and swirl intensities). The applied method compensates for the lower compression ratio, higher elasticity of the elongated piston, lower metal-surface temperatures, and higher blow-by of the optical engine. ${ }^{36,38,39}$ The blow-by is likely increased for the optical engine because the piston rings are run unlubricated in order to reduce window fouling. ${ }^{39}$ The metal-surface temperatures are expected to be lower in the optical engine due to the limited number of fired engine cycles, that is, the engine is not fully warmed up and stationary conditions are therefore not exactly reached. The lack of piston cooling may lead to a higher glass-surface temperature in the optical engine at fired operation, as compared to the all-metal engine. ${ }^{36,38,39}$ However, this effect is likely offset by the limited number of fired cycles of the optical engine.

The in-cylinder average bulk-gas conditions at injection timing are given in Table 3 for both engines under the current operating conditions (without PD). The data are derived basically from the measured pressure traces. Evidently, the pressures at injection timing are approximately equal, because the injection occurs near TDC, as shown in Table 2. The average bulk-gas temperature and density of the optical engine generally differ less than $10 \%$ as compared to the all-metal engine. However, the ignition delay times are approximately equal in both engines, as discussed in section "Ignition delay." This indicates that the local temperatures close to the fuel jets are very similar in both engines, although average bulk-gas conditions are slightly different. ${ }^{38}$ Presumably, this can be explained by slightly different temperature fields in these engines. ${ }^{39}$ According to
Colban et al. ${ }^{38}$ the ignition delay is used as a "thermometer" in this work. Thereby, not only the pressure but also the highly relevant temperature in the vicinity of the fuel jets are approximately equal in both engines. A very similar strategy was applied in Colban et al. ${ }^{38}$ The applied diagnostics for exhaust gas analysis at the allmetal engine and in-cylinder pressure measurements in both engines are described elsewhere. ${ }^{5}$

\section{Optical setup}

In order to visualize the $\mathrm{OH}^{*}$ chemiluminescence and the soot luminosity simultaneously, two intensified Complementary Metal Oxide Semiconductor (CMOS) cameras (LaVision HSS6, Photron SA1) are employed, allowing high spatial resolution for both channels. The optical setup is also shown in Figure 1. The flame luminosity exiting the engine is split up by a beam splitter (quartz glass plate). The reflected light is redirected by a second mirror before entering the objective of the first intensified camera through a RG 570 filter, which blocks the transmission of all wavelengths smaller than $570 \mathrm{~nm}$. The light transmitted by the beam splitter enters the ultraviolet (UV) objective of the second camera through the filter combination (DUG11X and BP313), as described in Pauls et al. ${ }^{13}$ This filter combination has its maximum transmission at $313 \mathrm{~nm}$ with a bandwidth of about $20 \mathrm{~nm}$. The maximum transmission is about $65 \%$, whereas it is lower than $10^{-5}$ in the wavelength range of $400-800 \mathrm{~nm}$. Any transmitted radiation in the wavelength range beyond $800 \mathrm{~nm}$ is not detected by the image intensifier (a similar wavelength dependence of the quantum efficiency was presented in Mueller and Martin ${ }^{32}$ ). Thereby, interfering soot luminosity and chemiluminescence from other species are substantially reduced in the $\mathrm{OH}^{*}$ measurements. Despite the applied optical filter, some soot-OH* crosstalk is expected, basically due to luminosity around $313 \mathrm{~nm}$, which increases with increasing temperature. ${ }^{40,41}$ However, it should be noted that the simultaneously measured soot and $\mathrm{OH}^{*}$ signal distributions are not necessarily similar in the high-temperature combustion process, for example, for significantly sooting diesel fuel. In particular, relatively low $\mathrm{OH}^{*}$ signals are often observed in strongly sooting regions in quasiinstantaneous images (not shown for brevity). This is consistent with Jakob et al. ${ }^{5}$ Overall, the results indicate that $\mathrm{OH}^{*}$ signals are not dominated by interfering

Table 3. Comparison of the apparent in-cylinder bulk-gas conditions for the all-metal and optical engines (without PD) at the start of injection for diesel and BLT.

\begin{tabular}{lllll}
\hline Fuel (engine) & Diesel (all-metal) & Diesel (optical) & BLT (all-metal) & BLT (optical) \\
\hline Pressure (bar) & 56.1 & $56.2(+0.2 \%)$ & 48.4 & $50.0(+3.3 \%)$ \\
Temperature $(\mathrm{K})$ & 896 & $863(-3.7 \%)$ & 860 & $808(-6.0 \%)$ \\
Density $\left(\mathrm{kg} / \mathrm{m}^{3}\right)$ & 21.5 & $22.6(+5.1 \%)$ & 20.0 & $22.2(+11.0 \%)$ \\
\hline
\end{tabular}

BLT: $70 \%$ butyl levulinate and 30\% n-tetradecane (by volume). Relative differences between the all-metal and optical engine are given in brackets. 
soot luminosity in the high-temperature reaction zone relatively close to the bowl rim. Even lower soot-OH* cross-talk is expected in the reaction zones in which the temperature is relatively low. These reaction zones are basically investigated in this article, so that the influence of cross-talk is generally weak. In contrast, both temperature effects and window fouling can cause significant uncertainty in the interpretation of the signal intensities. These potential sources of error are discussed in more detail in section "Results and discussion." A thorough discussion of uncertainty in the analysis of luminosity images was also presented in Mueller and Martin. ${ }^{32}$

The soot-OH* cross-talk is also expected to be weak because both the soot production and flame temperature are relatively low in the current engine. ${ }^{40,42}$ Reduced flame temperatures are partly achieved by a high fraction of exhaust gas in the charge $(38 \%$ for diesel fuel). The resulting peak flame temperature is estimated to be about $2100 \mathrm{~K}$ under this condition, whereas it would be about $2400 \mathrm{~K}$ without EGR. ${ }^{20,32}$ This leads to significantly reduced cross-talk. For instance, the blackbody radiation at the $\mathrm{OH}^{*}$ detection wavelength (around $313 \mathrm{~nm}$ ) is by a factor of about 15 lower at $2100 \mathrm{~K}$ as compared to $2400 \mathrm{~K}$, according to Wien's law. The behavior of real soot is expected to be essentially similar. ${ }^{41}$

Both cameras are operated with a frame rate of $18 \mathrm{kHz}$. This results in a temporal resolution of 0.5 ${ }^{\circ} \mathrm{CA}$ at $1500 \mathrm{~min}^{-1}$. From the fired engine cycles, the cycles 14-38 are used for the image data processing. Note that the engine needs a number of successive, fired cycles to reach a stable operating condition in terms of IMEP, and due to window fouling, the signal intensity decreases with increasing cycle number. For each series of images, a spatial calibration is applied to ensure a proper scaling and piston bowl-induced refraction correction of the images. The optical setup is described in more detail elsewhere. ${ }^{5}$ The image postprocessing is also discussed in Jakob et al. ${ }^{5}$ and the following sections.

\section{Results and discussion}

\section{Thermodynamic analysis}

The combustion behavior of BLT and conventional diesel fuel is first characterized using in-cylinder pressure traces for the current operating conditions. Figure 2 shows the results of typical ensemble-averaged cylinder pressure measurements for conventional diesel fuel (EN 590) in Figure 2(a), (c), (e), and (g), and for BLT in Figure 2(b), (d), (f), and (g). The data in Figure 2(a)(g) correspond to steady-state operation of the allmetal engine without PD, whereas Figure 2(a)-(f) shows the concerning results of the optical engine with and without PD, respectively. The actual duration of fuel injection and the corresponding motored pressure traces are also displayed in Figure 2(a) and (b). These data confirm that the in-cylinder pressure shortly before TDC is approximately equal in both engines. Furthermore, Figure 2(a)-(f) shows that the pressure rise and heat release in the early combustion phase, that is, the $\mathrm{CA}$ range from $0{ }^{\circ} \mathrm{CA}$ to $5{ }^{\circ} \mathrm{CA}$ after top dead center (ATDC), are comparable in both engines as expected. However, the pressure traces in Figure 2 also show that the peak pressure during combustion is higher in the all-metal engine than in the optical engine, basically due to the reduced compression ratio, slightly lower metal-surface temperatures, increased blow-by, and the increased elasticity of the elongated piston, as discussed in "Engines and operating conditions." The differences between the current optical and all-metal engines are taken into account in the data reduction. Most conclusions are based on the optical engine data only.

According to Janssen et al. ${ }^{1}$ the combustion duration, that is, the time period from $5 \%$ to $90 \%$ fuel conversion, decreased significantly $(45 \%)$ for BLT as compared to diesel fuel in the all-metal engine under comparable part-load conditions (1500 $\mathrm{min}^{-1}, 6.8$ bar IMEP, with pilot injection). Figure 2(a)-(d) shows that a similar behavior is found in both engines in the present experiments without pilot injection. The in-cylinder peak pressure is also slightly higher for BLT than for diesel fuel in the present and previous ${ }^{1}$ measurements in both engines. These findings will be explained by the optical data presented in the following sections.

Figure 2(a) and (b) also demonstrate that the ignition delay and combustion process are slightly different with and without PD, respectively, for both fuels. This will be discussed in more detail in the following sections.

Interestingly, distinct cool flame heat release is detected for BLT in both engines, that is, in Figure 2(b), by comparing the pressure traces of the motored and fired engines. According to Musculus, ${ }^{11}$ cool flame heat release may enhance fuel evaporation. However, Figure 2(b) indicates that this effect is negligible for BLT because the detected cool flame heat release hardly overlaps the injection event.

Note also that the indicated efficiency is slightly lower for BLT as compared to diesel fuel, as discussed in Janssen et al. ${ }^{1}$ This is partly caused by the $\mathrm{HC}$ and $\mathrm{CO}$ emissions, which are presented in the following section. In addition, thermodynamic process losses were identified for BLT in Janssen et al. ${ }^{1}$

\section{Engine-out emissions}

In this section, the engine-out emissions of BLT and diesel fuel are compared. The raw emissions produced by the all-metal engine without PD at the selected partload condition are displayed in Figure 3. The soot, HC, $\mathrm{CO}$, and noise emissions are given for BLT and diesel fuel as a function of $\mathrm{CN}$ because previous investigations demonstrated that this fuel parameter is particularly important for the emissions of light-duty diesel 


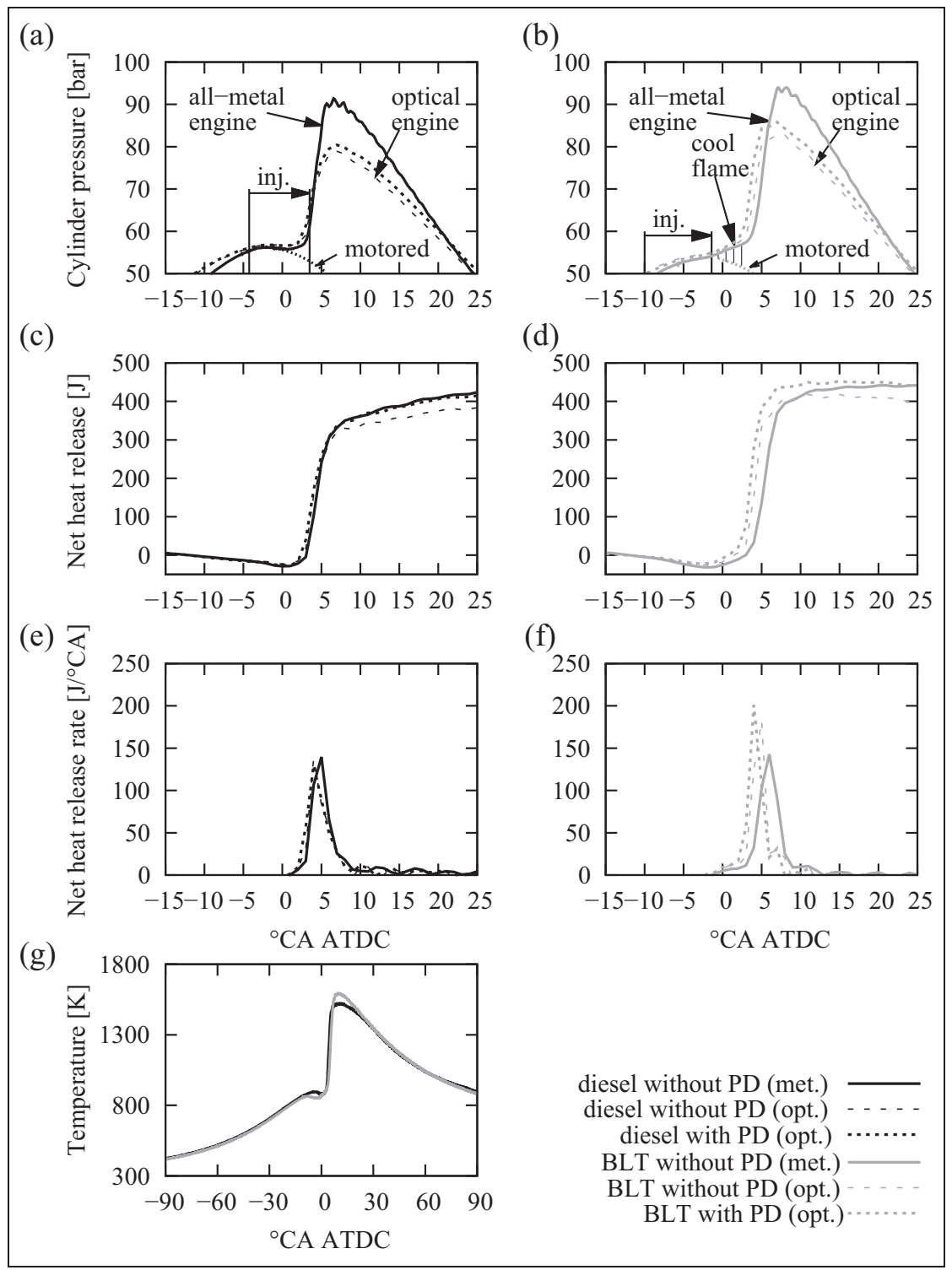

Figure 2. Thermodynamic analysis of the investigated fuels. The duration of actual fuel injection (inj.) is also shown in (a) and (b). The data in (a)-(f) arise from both the all-metal (met.) and optical (opt.) engines, whereas ( $\mathrm{g}$ ) corresponds to the met. engine only. CA: crank angle; ATDC: after top dead center; PD: port deactivation; BLT: $70 \%$ butyl levulinate and $30 \%$ n-tetradecane (by volume).

engines. ${ }^{3-5}$ The $\mathrm{NO}_{X}$ emissions are not presented in Figure 3, because they are kept constant, as noted previously.

Overall, the present results are consistent with those reported in Janssen et al. ${ }^{1}$ at comparable part-load operating conditions (with split injection). Figure 3(a) shows that the soot emissions increase with increasing $\mathrm{CN}$. However, $\mathrm{CO}, \mathrm{HC}$, and combustion sound emissions are (slightly) higher for BLT than for diesel fuel at equal $\mathrm{NO}_{X}$ emissions due to the enhanced fuel-air homogenization and pre-mixed combustion. This behavior is essentially consistent with the previously observed trends for other fuels. ${ }^{3,5}$ According to Zannis et al. $^{3}$ and Jakob et al. ${ }^{5}$ the drastically reduced soot emissions of BLT could be basically explained by its fuel-bound oxygen, the lack of aromatics, and the influence of $\mathrm{CN}$ on pre-combustion mixing. However, this is investigated in more detail in the following sections.

\section{Ignition delay}

In this section, the ignition behavior of BLT is characterized. Ignition delay and probability are inferred from the $\mathrm{OH}^{*}$ images for the optical engine. ${ }^{5}$ The ignition probability is the fraction of $\mathrm{OH}^{*}$ images in which $\mathrm{OH}^{*}$ is detected at a given CA in each spray plume. ${ }^{31}$ The ignition delay time is defined as the time after start of actual fuel injection until the ignition probability has reached $50 \% .^{31}$ Thus, the ignition delay is an ensembleaveraged quantity, whereas the ignition probability represents the cyclic variations in the second-stage ignition. Note that the optical ignition delay is also determined for the individual sprays of the multi-hole nozzle, as 

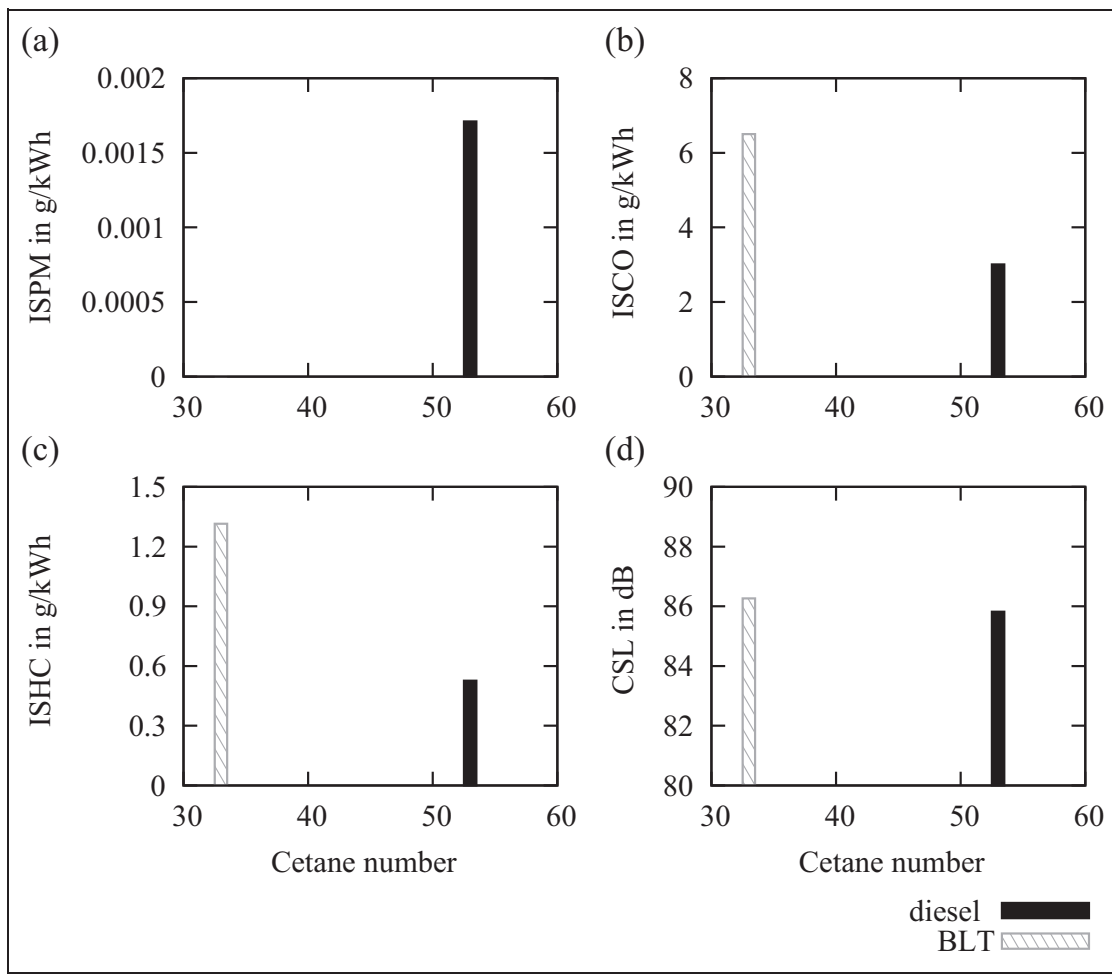

Figure 3. Engine-out raw emissions of the all-metal engine: (a) ISPM, (b) ISHC, (c) ISCO, and (d) CSL. Note that the ISPM of BLT is vanishing, and therefore not apparent in (a).

ISPM: indicated specific particulate matter; ISHC: indicated specific (unburnt) hydrocarbons; ISCO: indicated specific carbon monoxide; CSL: combustion sound level; BLT: $70 \%$ butyl levulinate and $30 \%$ n-tetradecane (by volume).

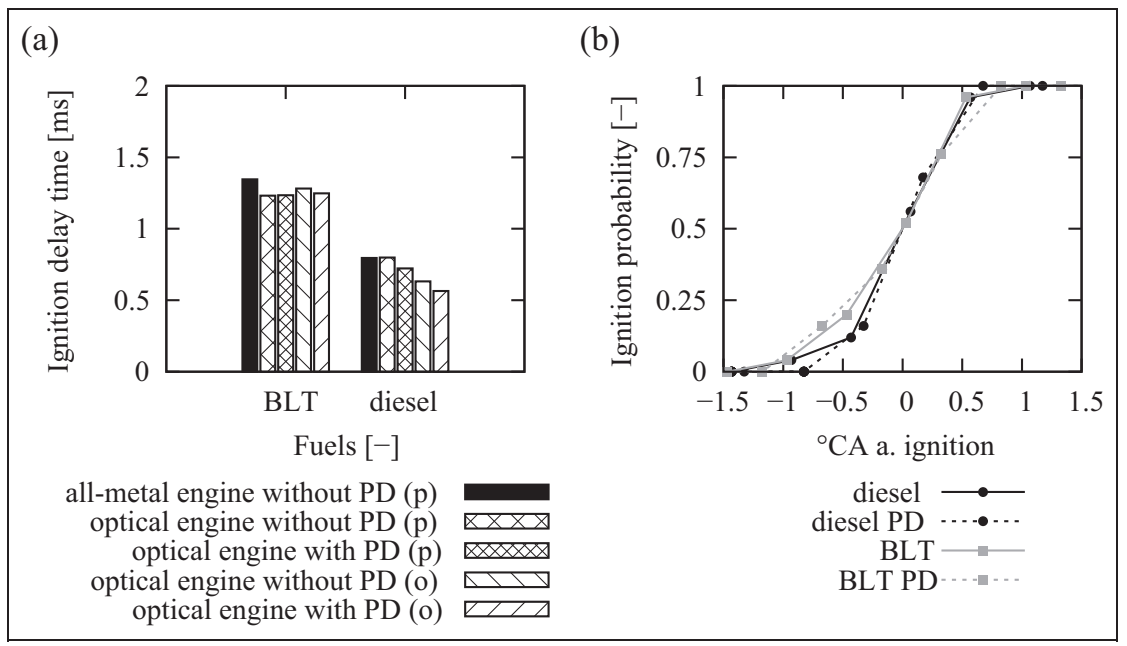

Figure 4. (a) Comparison of the ignition delay time of the optical and all-metal engine, in which the data are inferred from both the pressure traces (denoted "p") and the optical measurements (“o”) and (b) spread of the ignition probability for diesel fuel and BLT with and without PD.

BLT: $70 \%$ butyl levulinate and 30\% n-tetradecane (by volume); CA: crank angle; PD: port deactivation.

discussed in section "Effect of swirl intensity on diesel fuel combustion."

In addition, the ignition delay of both engines is determined from the (ensemble-averaged) pressure traces by calculating the time from the actual start of injection until an MFB of $5 \%$ is reached. ${ }^{1}$ Thus, a certain systematic difference between the ignition delays obtained from the different diagnostics may be expected. In fact, Figure 4(a) shows that the optically determined ignition delays are indeed shorter than the corresponding ones inferred from pressure traces for diesel fuel, but this is essentially not observed for BLT. The different behavior of the fuels is caused by the cool flame, which cannot be observed in the $\mathrm{OH}^{*}$ images, 
but it leads to a noticeable pressure rise for BLT, as noted previously. Note also that the ignition delays of both engines (determined from pressure data) are slightly different for BLT due to the altered shapes of the corresponding pressure traces shown in Figure 2.

However, Figure 4(a) also shows that the ignition delay increases significantly for both engines operating on BLT as compared to diesel fuel as expected, according to the fuel $\mathrm{CN}$ given in Table 2. The trend illustrated in Figure 4(a) essentially corresponds to the one observed for other alternative fuels in the same engines. $^{5}$

Additionally, Figure 4(a) demonstrates that the ignition delay for the optical engine is consistently shorter for diesel fuel with PD as compared to the operating condition without PD. According to Miles, ${ }^{23}$ this behavior was not universally observed in previous investigations. In fact, decreasing or increasing ignition delays were found with increasing swirl intensity in different studies described in Miles $^{23}$ and references therein, depending on the details of mixture preparation. The latter can vary based on several factors, for example, engine geometry and operating conditions. In contrast to diesel fuel, the ignition delays are essentially not affected by the application of PD for BLT, as shown in Figure 4(a). The swirl effect on ignition and combustion of BLT is discussed in more detail in section "Variation in swirl for BLT."

The average ignition probability, which is determined from the entire field of view of the $\mathrm{OH}^{*}$ images, is depicted in Figure 4(b). It is given as a function of degree CA after ignition, so that the curves for both fuels and operation conditions, respectively, coincide at a value of $50 \%$, although the ignition delays are different. Figure 4(b) essentially shows that the ignition stability, that is, the transition time in which the ignition probability increases from $0 \%$ to $100 \%$, is slightly larger for BLT as compared to diesel fuel. Accordingly, it was demonstrated previously for other alternative fuels that the ignition stability can generally be improved by increasing CN. ${ }^{4,5}$ Apparently, the ignition stability increased with decreasing ignition delay. However, Figure 4(b) also shows that the ignition stability is not noticeably different for the selected operating conditions with and without PD. The ignition process in the current optical engine is discussed in more detail in the following sections. The influence of soot-OH* cross-talk on the ignition delay and probability measurements is negligible because hardly any soot is formed at the ignition CA, as demonstrated in section "Ensemble-averaged $\mathrm{OH}^{*}$ and soot images."

\section{Field of view}

The field of view, which is used in the subsequent sections, is described in the following. Figure 5 illustrates the piston-crown window and the resulting field of view of the $\mathrm{OH}^{*}$ and soot luminosity images. A typical quasi-instantaneous, that is, single-shot, $\mathrm{OH}^{*}$

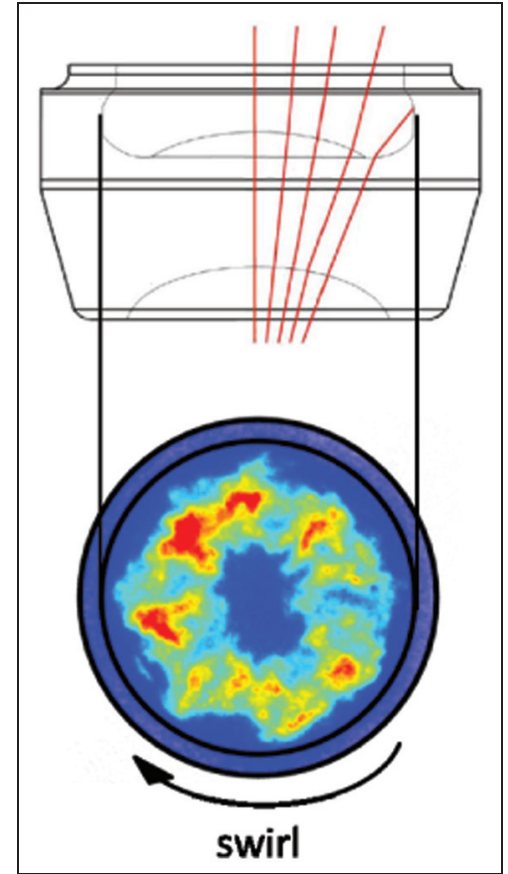

Figure 5. Piston-crown window and the field of view of the optical diesel engine; a typical single-shot $\mathrm{OH}^{*}$ image shows the fully developed combustion of BLT (at $3.5^{\circ} \mathrm{CA}$, without PD).

chemiluminescence image, showing the fully developed high-temperature combustion of BLT (at $3.5{ }^{\circ} \mathrm{CA}$, without PD), is displayed in Figure 5 as an example. A black circle shows the position of the piston bowl rim in this image. Note that a certain portion of the squish volume is visualized, but it appears contracted due to optical distortion. Some ray tracing results are also shown in Figure 5, in order to illustrate the distortion caused by the piston-crown window. Note also that the exhaust valves are located in the upper half of the images and the intake valves are located in the lower half of the images. The injector is positioned in the center.

The single-shot image depicted in Figure 5 shows that the high-temperature combustion of BLT is relatively homogeneous due to extensive pre-combustion mixing. In particular, the eight individual fuel sprays are, therefore, not recognized (in contrast to a comparable single-shot $\mathrm{OH}^{*}$ image for rather conventional diesel-like combustion in the same engine presented in Jakob et al. ${ }^{5}$ ).

\section{Ensemble-averaged $\mathrm{OH}^{*}$ and soot images}

In this section, the combustion and soot formation of both BLT and diesel fuel are discussed in more detail, based on ensemble-averaged optical data. Figures 6 and 7 show $\mathrm{OH}^{*}$ and soot luminosity images, which correspond to the measurements of the optical engine presented in Figures 2(a)-(f), 4, and 5, at selected CAs, in order to visualize the different phases of hightemperature combustion. They are averaged over 25 


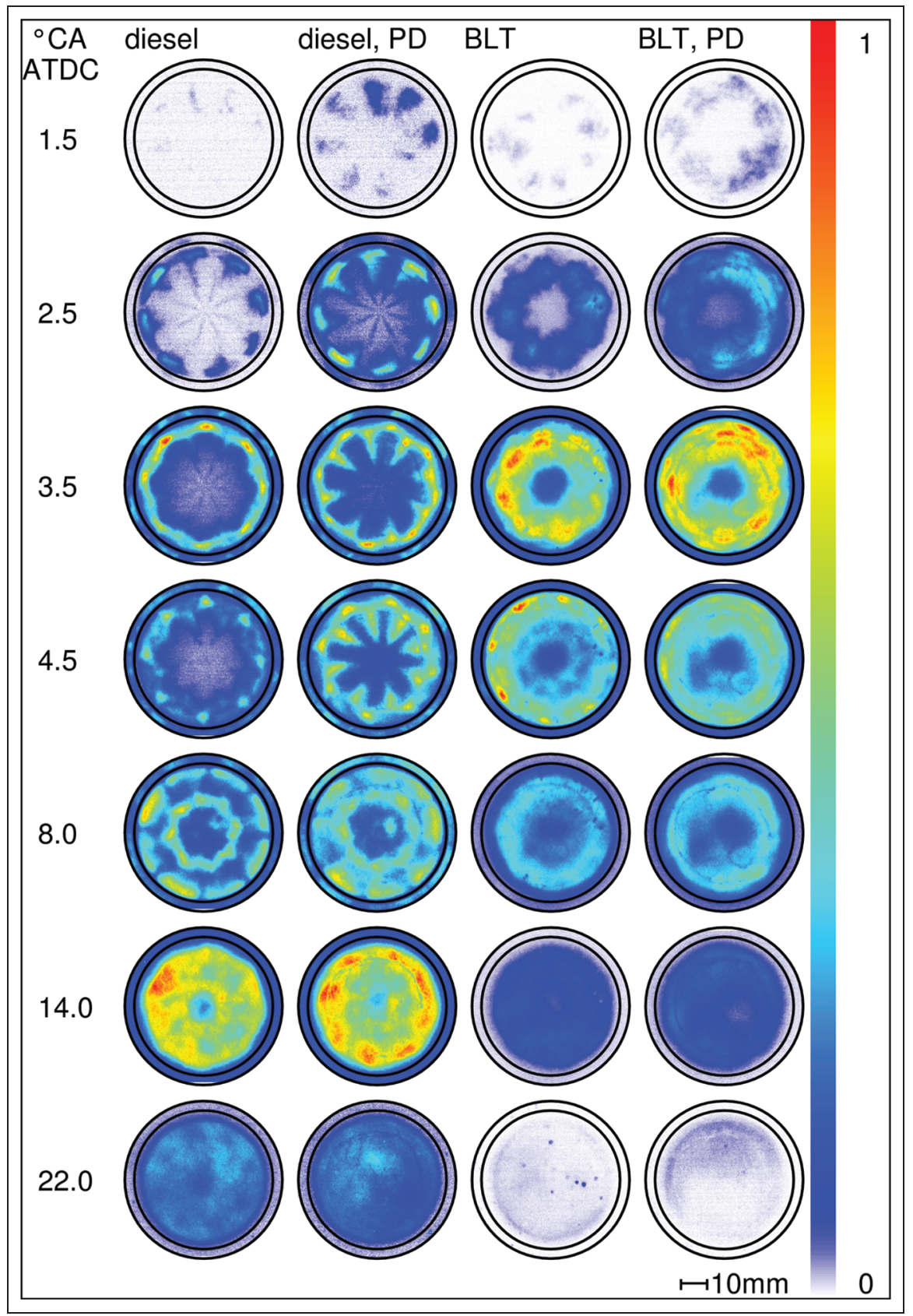

Figure 6. Temporal sequences of ensemble-averaged $\mathrm{OH}^{*}$ chemiluminescence intensities (normalized to the maximum of the series in each individual column; the images in the second and fourth columns correspond to engine operation with PD). CA: crank angle; ATDC: after top dead center; PD: port deactivation; BLT: $70 \%$ butyl levulinate and $30 \%$ n-tetradecane (by volume).

consecutive cycles. Overall, these images show that the combustion process is highly unsteady for both BLT and diesel fuel, that is, a quasi-steady combustion phase, which was previously observed for rather conventional combustion in heavy-duty engines, ${ }^{20,25}$ is not established. This is basically caused by relatively short durations of fuel injection, illustrated in Figure 2 and Table 2, as indicated by optical investigations on very similar combusting sprays in a constant-volume vessel. ${ }^{4}$ Accordingly, the pressure traces in Figure 2 indicate that high-temperature combustion occurs after the end of fuel injection, so that a quasi-steady flame is not established, which would be caused by a relatively long injection duration. This is confirmed by the $\mathrm{OH}^{*}$ images in Figure 6 at CAs from $2.5^{\circ}$ to $3.5^{\circ}$, which show that the injection overlaps the combustion event only in a short CA range for diesel fuel, and not any liquid fuel sprays are detected for BLT. In this work, fuel droplets are visualized if they are sufficiently illuminated by natural flame emission, so that Mie scattering is observed in the acquired images. ${ }^{5}$ This is particularly obvious in the second row $\left(2.5^{\circ} \mathrm{CA}\right)$ of Figure 6 for diesel fuel. However, the corresponding BLT measurements on the right-hand side of Figure 6 show indeed that there is no sign of fuel droplets, although strong $\mathrm{OH}^{*}$ chemiluminescence is detected. 


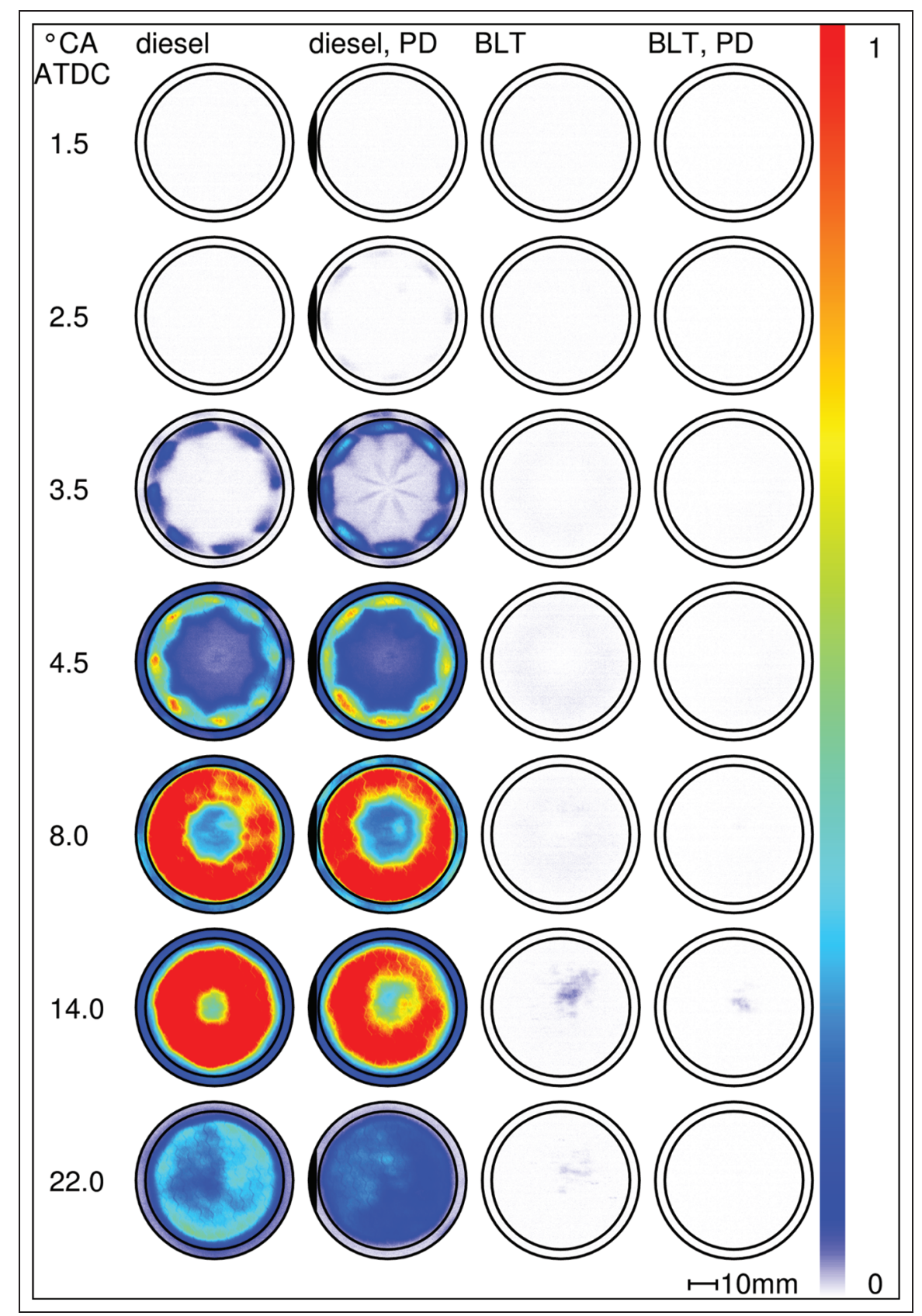

Figure 7. Temporal sequences of ensemble-averaged soot luminosity "raw" intensities; the images in the second and fourth columns correspond to engine operation with PD.

CA: crank angle; ATDC: after top dead center; PD: port deactivation; BLT: $70 \%$ butyl levulinate and $30 \%$ n-tetradecane (by volume).

Note also that evaporation of BLT is promoted by its relatively high volatility given in Table 2 , as discussed in more detail below.

In general, the $\mathrm{OH}^{*}$ and soot images for diesel fuel, which are shown in the first two columns of Figures 6 and 7 , respectively, are similar to the ones for alternative, single-component fuels presented in Jakob et al. ${ }^{5}$ By contrast, the corresponding images for BLT in the third and fourth columns of Figures 6 and 7 are drastically different. The $\mathrm{OH}^{*}$ images for diesel fuel in Figure 6 show that the individual combusting sprays are clearly recognized in the early combustion phase, that is, until about $5{ }^{\circ} \mathrm{CA}$, whereas relatively broad distributions of $\mathrm{OH}^{*}$ are observed for BLT. This confirms that the combustion of BLT is significantly more homogeneous, basically due to its low $\mathrm{CN}$, as suggested in the previous section. The soot luminosity images in Figure 7 essentially show that soot production is drastically reduced for BLT as compared to diesel fuel (with and without PD). It should be noted that the soot luminosity increases strongly with increasing temperature $^{19,32}$ (thus, the luminosity generally decreases strongly in the late combustion phase). However, Figure 2(g) indicates that the in-cylinder peak temperature is higher for BLT than for diesel fuel. Hence, the large difference between the soot luminosity signals for 
those fuels is not likely caused by the temperature effect. The same holds for the influence of window fouling on the signal intensity because significant window fouling is observed only for diesel fuel. It can be concluded that the vanishing soot emissions of BLT, which are illustrated in Figure 3(a), are basically caused by greatly decreased soot formation, rather than by soot oxidation, because essentially not any soot is detected particularly in the early combustion phase, that is, up to a CA of $8.5^{\circ}$, for BLT. The only soot produced by BLT is found in the central portion of the field of view after a CA of $9^{\circ}$, as shown in Figure 7 (at $14^{\circ}$ and $22^{\circ}$ ). It is caused by a small amount of fuel, which emanates from the nozzle at about $5{ }^{\circ} \mathrm{CA}$, that is, well after the regular end of injection..$^{5}$ Obviously, mixture formation is poor for this small fuel mass, so that soot is formed. However, Figure 3(a) illustrates that it does not noticeably contribute to the engine-out emissions.

Note also that essentially the same phenomenon occurs for diesel fuel. In particular, the luminosity images at $8.0{ }^{\circ} \mathrm{CA}$ in the first two columns of Figure 7 demonstrate that a small amount of soot is formed close to the center of the field of view (it can hardly be detected at later CAs, which are given in Figure 6, because its luminosity is swamped by the much stronger signal intensity arising from the combusting, redirected sprays of the regular injection). The corresponding $\mathrm{OH}^{*}$ images in Figure 6 show that an isolated region of near-stoichiometric combustion is observed simultaneously in the same portion of the field of view (overlapping regions of near-stoichiometric and sooting combustion are often found in the present measurements, basically due to the limited spatial resolution of the applied line-of-sight diagnostic). ${ }^{5}$ In addition, overlapping soot and $\mathrm{OH}^{*}$ signals are partly caused by the optical interference discussed in section "Optical setup." Interestingly, a similar process of combustion of a small amount of fuel that emanated from the nozzle after the regular end of injection was previously also detected in another HSDI engine, which was equipped with a first-generation passenger-car common-rail injection system. ${ }^{21}$ Figure 7 shows that this process contributes little to soot production for diesel fuel, but it is the dominant source of soot for BLT.

It is plausible that the observed extensive pre-mixing of BLT contributes significantly to the greatly reduced soot formation because the fuel-air mixture is relatively fuel lean prior to combustion. This is basically caused by the low CN of BLT, as noted previously. However, mixture formation and the resulting emissions also depend on the evaporation characteristics of a fuel, in particular if wall impingement of the liquid fuel occurs. ${ }^{11}$ According to the volatility data given in Table 2, the penetration length of BLT may be shorter than the one of diesel fuel. In this case, wall impingement of BLT would not be expected, because wall impingement of diesel fuel does not occur either, due to the design of the piston bowl. According to Siebers, ${ }^{43,44}$ the liquid-phase penetration of a multi-component fuel is controlled by the higher boiling point components. The conventional diesel fuel contains less volatile components than the BLT, as indicated by the volatility data in Table 2. However, the penetration length also depends on the ambient conditions. It is promoted by the advanced injection timing for BLT. However, significant wall impingement of BLT is not expected because combusting liquid fuel films on surfaces are not observed in the optical measurements.

According to Kosaka et al. ${ }^{45} \mathrm{OH}$ and soot hardly coexist in diesel flames. Soot was found in the central region, whereas $\mathrm{OH}$ was located at the periphery. Laser-sheet imaging was applied in Kosaka et al. ${ }^{45}$ In contrast, overlapping $\mathrm{OH}^{*}$ and sooting regions are observed in Figures 6 and 7 due to the limitations of the current line-of-sight diagnostic discussed above. In addition, the soot-OH* overlap is increased by cycle averaging in Figures 6 and 7. By contrast, highly timeresolved measurements were discussed in Kosaka et al. ${ }^{45}$ However, Figures 6 and 7 show that $\mathrm{OH}^{*}$ appears earlier than soot. Accordingly, $\mathrm{OH}^{*}$ is found closer to the nozzle compared to soot in the developing spray plumes, in particular at $3.5^{\circ} \mathrm{CA}$ and $4.5^{\circ} \mathrm{CA}$ ATDC for diesel fuel. These findings are consistent with Kosaka et al. ${ }^{45}$

Figure 8 shows the $\mathrm{OH}^{*}$ and soot luminosity intensities of the measurements presented in Figures 5-7. They are averaged over the entire field of view. The data represent approximately the entire high-temperature combustion process, although a certain fraction of the squish volume is not optically accessible, because the images in Figures 5 and 6 demonstrate that combustion in the squish volume is very weak, in particular for BLT.

The data in Figure 8 show the relative intensities of the different combustion phases, although they are affected by temperature effects and window fouling. ${ }^{5}$ In addition, soot-OH* $\mathrm{OH}^{*}$ cross-talk has to be considered. The shapes of the $\mathrm{OH}^{*}$ curves for both BLT and diesel fuel in Figure 8(a) and (b), respectively, essentially show that combustion is predominantly pre-mixed up to a CA of about $6^{\circ}$ ATDC, whereas it is basically mixing-controlled after $6{ }^{\circ} \mathrm{CA}$. However, these curves also show that the process of pre-mixed combustion is different for these two fuels because two distinct premixed burn spikes are recognized for diesel fuel only. The first one essentially corresponds to the initial premixed combustion phase observed previously for conventional, long injection durations. ${ }^{25}$ By contrast, the second pre-mixed burn spike, which is observed in Figure 8 (b) at about $5.5{ }^{\circ} \mathrm{CA}$, is caused by the short injection duration, which is typically used for HSDI engines. It arises from a volumetric auto-ignition and combustion process in the fully evaporated, trailing edge of the fuel distribution after the end of injection. It is discussed in more detail for alternative diesel-like fuels in Jakob et al. ${ }^{5}$ It is also shown in the corresponding $\mathrm{OH}^{*}$ images at $8^{\circ} \mathrm{CA}$ in Figures 6 and 9, as discussed in the following section. Two distinct pre-mixed 


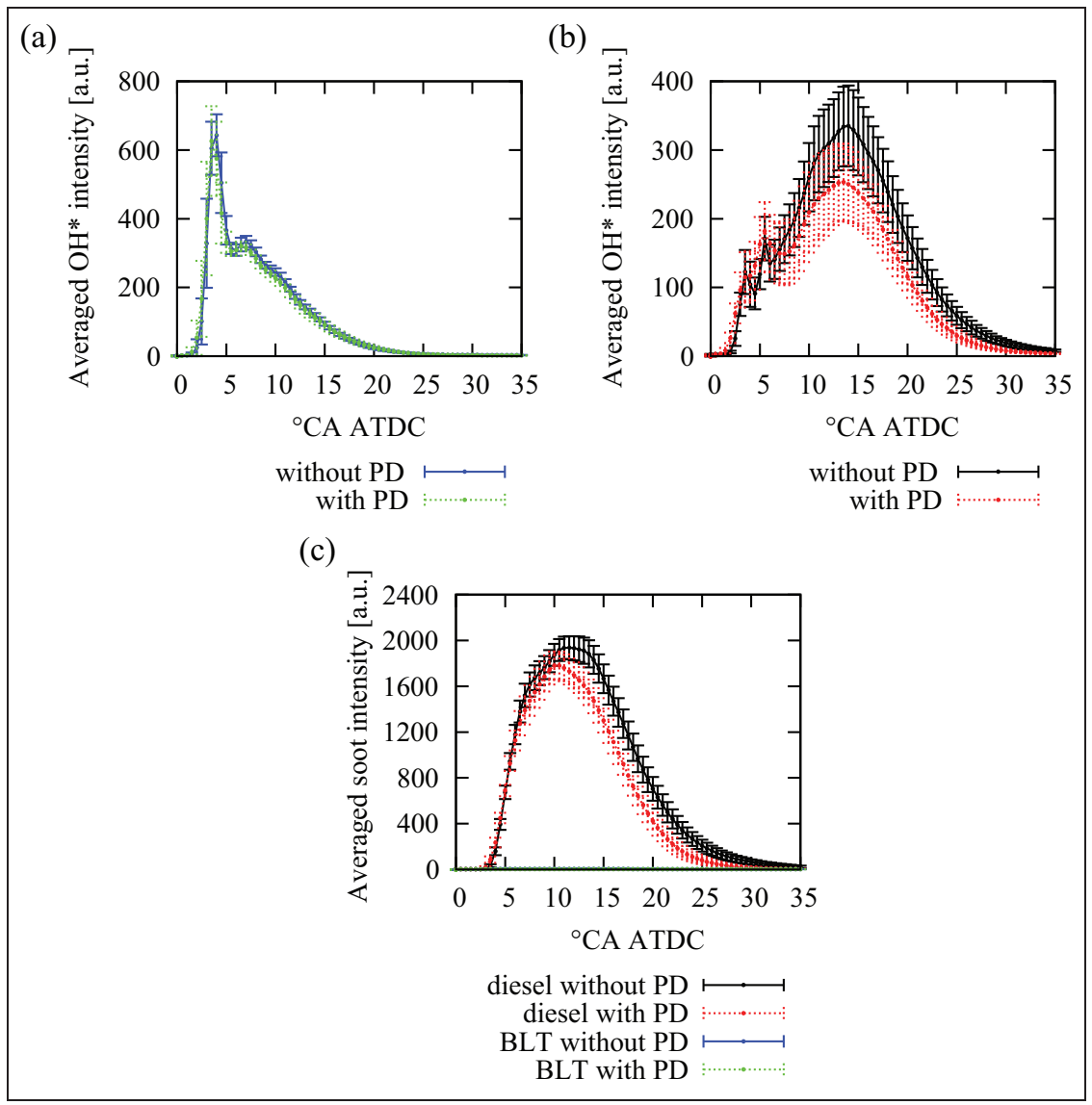

Figure 8. Spatially averaged signal intensities for both BLT and diesel fuel as a function of degree $\mathrm{CA}$ : (a) $\mathrm{OH}^{*}$ chemiluminescence (BLT), (b) $\mathrm{OH}^{*}$ chemiluminescence (diesel fuel), and (c) soot luminosity (recall that the luminosity for BLT is very weak, and therefore hardly apparent here).

CA: crank angle; ATDC: after top dead center; PD: port deactivation; BLT: $70 \%$ butyl levulinate and $30 \%$ n-tetradecane (by volume).

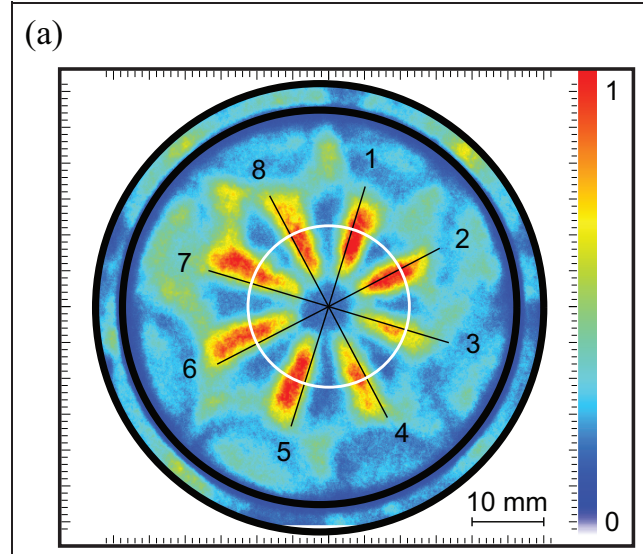

(b)

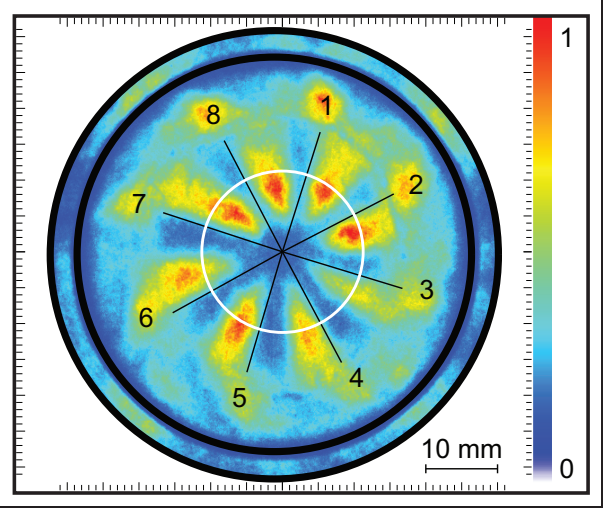

Figure 9. Ensemble-averaged $\mathrm{OH}^{*}$ chemiluminescence intensities at $5.5^{\circ} \mathrm{CA}$ (normalized to the maximum) of diesel fuel with the spray axes (black lines) and the radius where the swirl is measured (white circle): (a) low swirl and (b) high swirl.

burn spikes are not found for BLT because the fuel in the leading and trailing edges of the fuel distribution is well mixed prior to high-temperature combustion due to the long ignition delay.

With regard to soot formation, it should be noted that the fraction of pre-mixed combustion is significantly higher for BLT than for diesel fuel, as shown by the overall shapes of the $\mathrm{OH}^{*}$ curves in Figure 8(a) and (b). One might think that this effect was caused by soot-OH* cross-talk for diesel fuel. However, this interference is relatively weak, as noted in section "Optical setup," so that the discussed 
qualitative behavior of the signal intensity traces in Figure 8 cannot solely be explained in this way. Accordingly, these $\mathrm{OH}^{*}$ data also show that the duration of the entire combustion process is shorter for BLT than for diesel fuel. This is consistent with the results of the cylinder pressure measurements presented in Figure 2.

The averaged intensities of the soot luminosity measurements shown in Figure 8(c) correspond to diesel fuel only. Note that the detected soot luminosity from BLT is substantially weaker, so that it is hardly apparent in Figure 8(c) (although the signal intensities for BLT are enhanced by reduced window fouling and a slightly higher temperature during combustion, as indicated by the pressure traces in Figure 2). This confirms that the soot production is drastically reduced by using BLT, as noted previously.

The cycle-by-cycle variability (standard deviation) in the spatially integrated light intensity is also shown as bars in Figure 8. Note that particularly strong variations in the $\mathrm{OH}^{*}$ chemiluminescence occur for BLT, that is, in Figure 8(b), at a CA of about $2^{\circ}$ (the corresponding peak coefficient of variation $(\mathrm{COV})$ is about $100 \%$ ). This can be basically explained by the strongly increasing $\mathrm{OH}^{*}$ intensity shortly after ignition and the reduced ignition stability of BLT. Essentially, the same behavior was previously observed for other alternative fuels with varying ignition delays, that is, CNs., ${ }^{4,5}$ However, it should also be noted that the relative cyclic fluctuations of the $\mathrm{OH}^{*}$ intensity are lower for BLT than for diesel fuel during most of the high-temperature combustion process, that is, in the $\mathrm{CA}$ range of about $7^{\circ}-17^{\circ}$ (window fouling is taken into account). Accordingly, the COV of the IMEP is higher for diesel fuel $(1.4 \%)$ than for BLT $(1.0 \%)$ both with and without PD $\left(\mathrm{COV}\right.$ is defined in Heywood $\left.{ }^{46}\right)$. It is plausible that this is caused by the extensive pre-mixing of BLT. Overall, CN appears to be the most important fuel property with regard to cycle-by-cycle variations in high-temperature combustion. (The increased cyclic variability in the diesel- $\mathrm{OH}^{*}$ data can hardly be explained by soot-OH* cross-talk because the corresponding variability in the soot luminosity data is relatively low, as shown in Figure 8(c).)

The features of the $\mathrm{OH}^{*}$ and soot images discussed so far hold for both swirl intensities, that is, engine operation with and without PD. However, the data in Figures 5-8 are obviously different for these two operating conditions. This is discussed in the following sections.

Note that the discussed mechanism of soot reduction for BLT is similar to the strategy of previously proposed homogeneous charge compression ignition (HCCI), modulated kinetics (MK), and lowtemperature combustion (LTC) concepts, which are described in more detail in Musculus ${ }^{11}$ and Singh et al. $^{27}$ and the references therein. All these concepts provide relatively homogeneous pre-combustion mixtures, which are overall fuel lean and/or highly diluted by

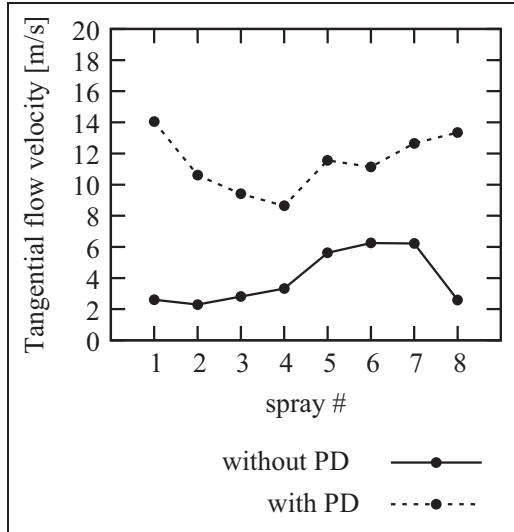

Figure 10. Tangential gas-phase flow velocities at the individual spray axes and at a radial distance of $10 \mathrm{~mm}$ (corresponding to the white circles in Figure 9).

PD: port deactivation.

EGR. Pre-mixing is generally enhanced using long ignition delays. In this way, soot emissions could be dramatically reduced, but at least the HCCI and $\mathrm{MK}$ concepts potentially lead to increased $\mathrm{CO}$ and $\mathrm{HC}$ emissions.

\section{Flow measurement}

The in-cylinder flow field is measured with and without PD as described in Appendix 1. The tangential flow velocity is determined quantitatively at a radial distance of $10 \mathrm{~mm}$ as an example. The investigated radial distance is illustrated by a white circle in Figure 9. The velocity is inferred from the displacement of the combusting fuel distribution trails with regard to the spray axes, as illustrated in Figure 9, and the delay between the end of injection, that is, $3.5^{\circ} \mathrm{CA}$, and $5.5^{\circ} \mathrm{CA}$. The resulting tangential velocity component is presented in Figure 10. It shows that there are local deviations from the solid-body velocity distribution, as suggested previously. Accordingly, inhomogeneities were found in the flow field by particle image velocimetry (PIV) measurements, conducted on a stationary test bench for the current port layout. ${ }^{17}$ However, the current flow tagging velocity measurements are preferred for the investigation of the direct influence of the air swirl on mixture formation and combustion, which is given in the following section, in particular because they are conducted temporally and spatially close to the injection and combustion event.

Figure 10 also shows that the mean swirl velocity close to the TDC is roughly a factor of 2 higher for the operating condition with PD as compared to the base condition. This is consistent with previous swirl measurements during induction on a stationary test rig. ${ }^{47}$ This indicates that the decay of the swirl intensity between induction and TDC, which is discussed in more detail in Heywood, ${ }^{46}$ is similar for both operating conditions. 


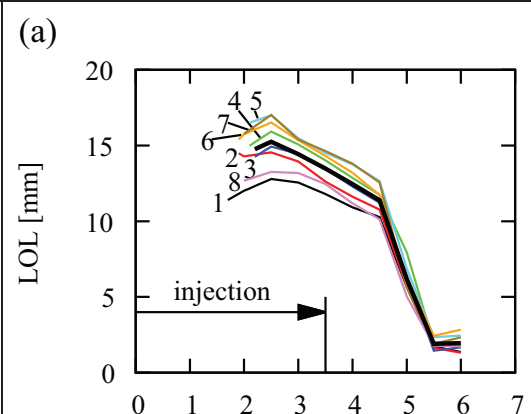

(c)

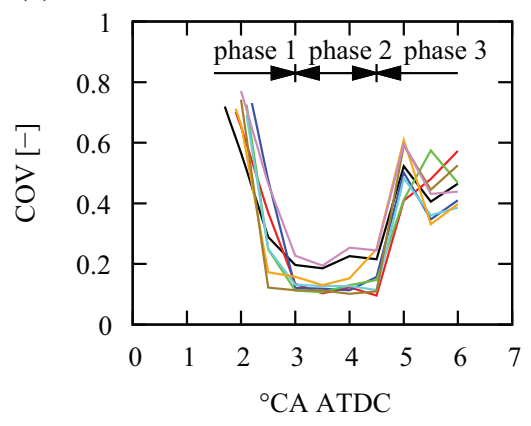

(d)

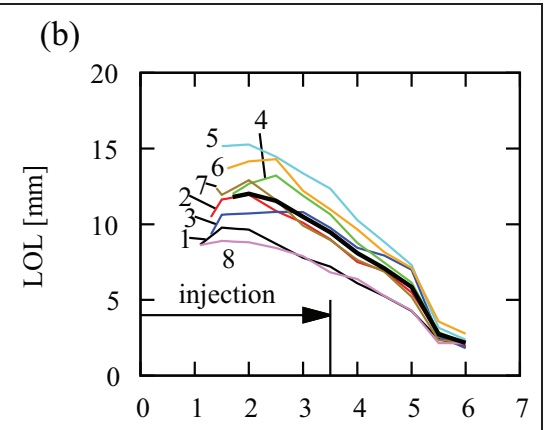

Figure I I. (a) LOL of each diesel fuel spray (averaged over 25 cycles) without PD as a function of ${ }^{\circ} \mathrm{CA}$, (b) LOL for diesel fuel with PD, (c) COV of the LOL from (a), and (d) COV of the LOL from (b).

LOL: lift-off length; COV: coefficient of variation; CA: crank angle; ATDC: after top dead center.

\section{Effect of swirl intensity on diesel fuel combustion}

In the following, the effect of in-cylinder air swirl on combustion is discussed for diesel fuel. Figure 8(b) shows that the average $\mathrm{OH}^{*}$ signal intensity is approximately equal with and without PD during pre-mixed combustion, that is, up to about $6{ }^{\circ} \mathrm{CA}$ ATDC, whereas it is lower with $\mathrm{PD}$ in the mixing-controlled phase after $6{ }^{\circ} \mathrm{CA}$. Overall, the $\mathrm{OH}^{*}$ signal intensity is relatively low with PD due to slightly increased window fouling. (However, this does not imply that soot formation is enhanced with PD. ${ }^{40,48}$ ) Note also that the observed difference of the $\mathrm{OH}^{*}$ signals after $6{ }^{\circ} \mathrm{CA}$ ATDC in Figure 8 (b) cannot solely be explained by optical soot$\mathrm{OH}^{*}$ cross-talk because the corresponding difference of the luminosity traces in Figure 8(c) is lower, in particular at earlier CAs (window fouling and temperature effects are taken into account). In conclusion, Figure 8(b) shows that the fraction of pre-mixed combustion is slightly higher with PD. Consequently, the heat release is increased in the early combustion phase with PD, as indicated by Figure 2(c) and (d). Accordingly, Figure 2(a) and (b) also show that the cylinder pressure increases more rapidly in the $\mathrm{CA}$ range from $4{ }^{\circ} \mathrm{CA}$ to $6{ }^{\circ} \mathrm{CA}$ ATDC with PD.

Comparable studies demonstrated that the combustion intensity was reduced with increasing swirl very late in the cycle, that is, in the final burnout phase. ${ }^{24}$

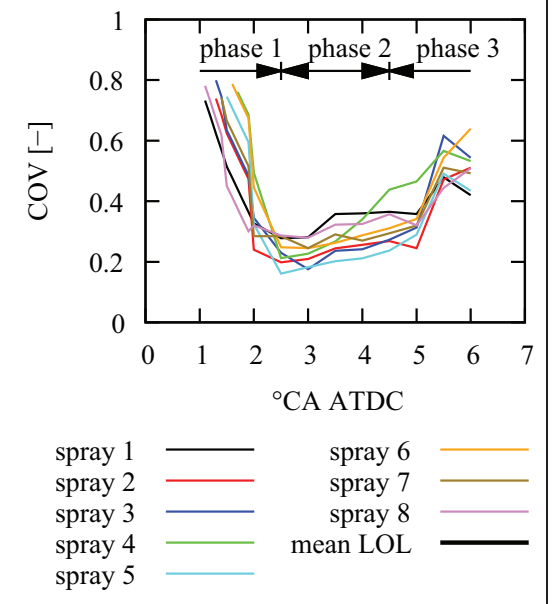

This is consistent with the present results. Note also that enhanced pre-mixed combustion for high-swirl conditions was not reported in Miles ${ }^{23}$ and Koyanagi et al. ${ }^{24}$ (with and without pilot injection, respectively), but it was observed in Van Gerpen et al. ${ }^{49}$ and Winterbone et al. ${ }^{50}$

The LOL, that is, the distance between the measured $\mathrm{OH}^{*}$ distribution and the corresponding nozzle-hole exit, is discussed in the following, in order to characterize high-temperature combustion in the present optical engine in more detail. The method to determine the LOL and its cyclic variability (COV) are discussed in Appendix 2. The resulting ensemble-averaged LOL and COV are displayed in Figure 11. The mean LOL, which is averaged over the eight individual sprays, is also shown. The curves commence at the ignition delay, that is, at an ignition probability of $50 \%$.

Overall, the LOL decreases in the considered CA range due to the end of the injection event, which is also illustrated in Figure 11..$^{5}$ As shown in Figure 11(a) and (b), the mean LOL decreases generally with increasing swirl. This corresponds to the reduced ignition delay, which is found with PD, as discussed in section "Ignition delay" because previous research indicated that the LOL is strongly affected by autoignition processes. , $5,12,13,19$ Accordingly, Figure 11(a) and (b) also demonstrate that the ignition delay of the 
individual sprays generally increases with increasing LOL for both operating conditions. However, the effect of auto-ignition processes on the LOL is still under scientific debate, as summarized recently in Jakob et al. ${ }^{5}$ The LOL may also be affected by other parameters, such as the local equivalence ratio and temperature. Furthermore, these data show that the dispersion of LOLs of the individual sprays is increased for the operating condition with PD, that is, in Figure 11(b). These findings are consistent with the $\mathrm{OH}^{*}$ images shown in Figure 6. In particular, the images in the first two columns at $1.5^{\circ} \mathrm{CA}$ ATDC demonstrate that initial ignition occurs earlier in the sprays that are located in the upper half of the field of view. The corresponding images in the CA range from $2.5^{\circ}$ to $4.5^{\circ}$ ATDC also show that the azimuthal asymmetry in the $\mathrm{OH}^{*}$ distribution is particularly pronounced for engine operation with PD. Accordingly, the cycle-by-cycle variability, $\mathrm{COV}$, in the spatially integrated $\mathrm{OH}^{*}$ signal is generally slightly higher for all CAs with PD (the corresponding standard deviation is shown in Figure 8(a)).

All these findings (including those reported in Appendix 2) can be basically explained by swirl and temperature effects, as demonstrated in the following. Obviously, the mean LOL decreases with increasing swirl, as noted previously, but it can be assumed that this is also partly caused by the swirl-induced temperature increase during combustion, which is indicated by the enhanced heat release shown in Figure 2(c) and (d). This effect is likely enhanced by the interaction of adjacent sprays. According to Musculus, ${ }^{14}$ the LOL generally decreases with decreasing interjet spacing angle. It is plausible that this is basically caused by thermal coupling between the sprays. ${ }^{10}$

It can also be assumed that the reduced ignition delay of the sprays in the upper half of the images is basically caused by the proximity to the relatively hot exhaust valves (recall that the exhaust valves are located there). As shown in Figure 10, the swirl velocity is relatively high for the operating condition with PD in the upper half of the images, that is, for sprays \#7, \#8, \#1, and \#2 (the individual sprays are numbered according to Figure 9). Thus, the relatively low LOL of these sprays with PD, which is particularly obvious in the second phase of the pre-mixed combustion process displayed in Figure 11, can be explained by both the relatively high temperature and the increase in swirl in this portion of the combustion chamber.

By contrast, the dispersion of the LOL curves without PD, which is shown in Figure 11(a), is smaller than the one for engine operation with PD because the assumed temperature distribution and measured swirl velocity do not coincide without PD, as illustrated in Figure 10. Figure 11(a) shows that the LOL of the sprays \#5, \#6, and \#7 is relatively high without PD, although the local swirl velocity is also relatively high for these sprays. Thus, it can be concluded that the influence of flow velocity on the LOL is more than compensated by the temperature effect induced by the proximity to the exhaust valves without PD.

Overall, it can be stated that the direct influence of swirl on the (average) LOL is only clearly observed if the variation in swirl is strong, and if it is not compensated by a counteracting temperature distribution. For instance, this holds for sprays \#1 and \#8, which are affected by substantially different swirl velocities with and without PD, respectively, as shown in Figure 10. Consequently, the LOL of these two sprays differs significantly with and without PD, respectively, as shown in Figure 11(a) and (b).

It is also interesting to note that a certain cylindrical asymmetry of the individual combusting sprays was consistently observed for increases in swirl, but not any significant influence of swirl on the (average) LOL or the ignition locations was reported in comparable studies. ${ }^{14,21,23}$ According to the present results, the latter could be explained either by the investigated swirl variation, which could have been too small, or the swirl effect was likely offset by the influence of other parameters, for example, the local temperature, in the previous experiments. However, it is not surprising that the LOL depends on the local swirl velocity because a certain influence of the swirl on the ignition delay was often observed, for example, in Miles ${ }^{23}$ and the references therein, and the LOL is strongly affected by autoignition processes, as noted previously.

\section{Sooting tendency of diesel fuel}

In this section, the swirl effect on soot production is discussed for diesel fuel. Soot emissions generally decrease with increasing swirl for the current and previously studied engines. ${ }^{18,21,23}$ For instance, this is indicated by the data shown in Figure 8(c). Details are not given here for brevity.

Laser-induced incandescence (LII) measurements demonstrated that soot production increases locally with decreasing local flow velocity in the current and previous engines. ${ }^{18,42}$ According to Adomeit et al. ${ }^{18}$ Taschek et al. ${ }^{21}$ Miles, ${ }^{23}$ and Koyanagi et al. ${ }^{24}$ reduced soot emissions at high-swirl conditions may be caused by either reduced soot formation or enhanced soot oxidation. The data in Figure 8(c) and Adolph et al. ${ }^{42}$ show that the swirl-induced difference in soot production is found relatively early in the cycle. This indicates that it is caused by soot formation rather than soot oxidation.

Previous research demonstrated that soot formation generally increases with decreasing LOL. ${ }^{4,5,8-11}$ Thus, it is at first somewhat surprising that the mean LOL is found to be lower with PD, and that particularly short LOLs of the individual sprays are observed in the lowsooting region in the upper half of the images with PD, as shown in Figure 11(a) and (b). However, this can be explained by the fact that the structure of the combusting sprays is substantially affected by high-swirl conditions, as demonstrated in the following. 


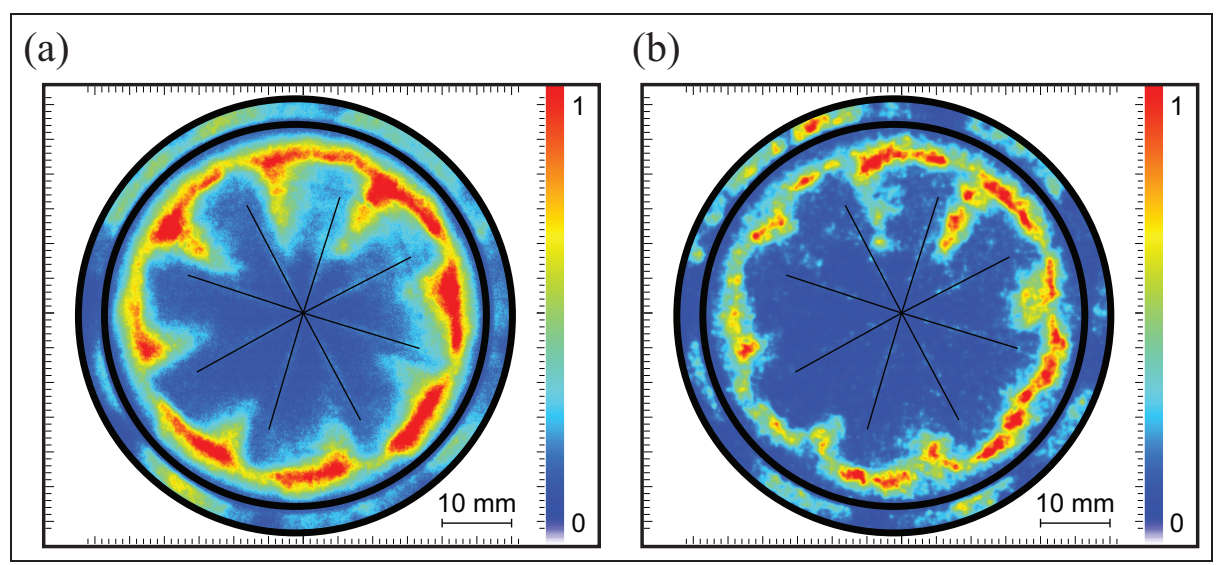

Figure 12. $\mathrm{OH}^{*}$ chemiluminescence intensities (normalized to the maximum) of diesel fuel with PD at $3^{\circ} \mathrm{CA}$ : (a) ensembleaveraged and (b) single-shot.

Black lines illustrate the spray axes.

According to Idicheria and Pickett, ${ }^{8}$ Siebers and Higgins, ${ }^{9}$ Chartier et al. ${ }^{10}$ and Pickett and Siebers, ${ }^{51}$ the diffusion flame at the periphery of the spray most likely prevents direct air entrainment into the inner core downstream of the LOL (at low-swirl conditions), so that most of the soot is generally formed in the inner, fuel-rich reaction zone. Thus, the LOL is important for soot formation under these conditions. Consequently, one might think that relatively low LOLs may lead to enhanced soot formation in the current engine, in particular during injection. However, the flame structure in this situation is illustrated in more detail in Figure 12, which shows typical ensemble-averaged and single-shot $\mathrm{OH}^{*}$ images at $3{ }^{\circ} \mathrm{CA}$ with $\mathrm{PD}$. The spray axes are also visualized by black lines in this figure. Obviously, the spray axes are generally outside the high-temperature flames because the flames are substantially shifted downstream by the strong, clockwise air swirl. This is particularly apparent in the single-shot image shown in Figure 12(b). Thus, air entrainment into the liquid fuel distribution is essentially not blocked by the hightemperature flame, although relatively low LOLs are observed, in particular in the upper half of the images. In conclusion, the LOL is not very important for soot formation under these conditions. Note also that previously presented conceptual models of cylindrically symmetric diesel flames in Chartier et al. ${ }^{10}$ Musculus ${ }^{11}$, Dec, ${ }^{25}$ Bruneaux, ${ }^{26}$ Singh et al. ${ }^{27}$ Bruneaux, ${ }^{28}$ and Kosaka et al. ${ }^{29}$ are not readily applicable to the combusting sprays shown in Figure 12, which are highly asymmetric.

However, it is plausible that pre-combustion mixing is enhanced by the swirling flow in the situation illustrated in Figure 12, as suggested in Taschek et al. ${ }^{21}$ and Miles. ${ }^{23}$ Consequently, soot formation is reduced for engine operation with PD, in particular in the upper half of the field of view.

In the following, the soot oxidation process late in the cycle is discussed. It is often believed that soot oxidation depends on the penetration length of the combusting sprays because this may affect air utilization. ${ }^{52}$ Both $\mathrm{OH}^{*}$ and soot images in Figures 6 and 7 show the dynamic penetration of the combusting sprays, which are redirected toward the cylinder axis by wall impingement, in particular after a $\mathrm{CA}$ of $4.5^{\circ}$. The average, radial penetration of the combustion gases is inferred quantitatively from the soot images, as depicted in Figure 13. Obviously, spray penetration is slower with PD. This is consistent with Taschek et al. ${ }^{21}$ and Miles. ${ }^{23}$ It can be explained by enhanced early air entrainment and tangential spray deflection under highswirl conditions. ${ }^{23}$

One might think that air utilization would, therefore, be improved without PD, allowing enhanced soot oxidation. $^{23,24,42}$ However, air utilization by faster spray penetration is a less important factor for soot oxidation if the oxygen concentration within the flame is still sufficiently high even late in the cycle. It should be noted that the flame temperature also impacts soot oxidation. ${ }^{24}$ Soot oxidation is expected to "freeze" if the temperature is lower than about $1300 \mathrm{~K}$. In fact, quantitative oxygen concentration and temperature measurements in a similar HSDI engine relatively late in the cycle (up to $40{ }^{\circ} \mathrm{CA}$ ATDC) demonstrated that the oxygen concentration in the combustion gases was always sufficiently high for soot oxidation, but the temperature was found to be lower than $1300 \mathrm{~K}$, in particular close to the cylinder centerline. ${ }^{40}$ The latter was explained by mixing of the leading portions of the combusting sprays with the relatively cold air close to the cylinder axis. Consequently, the late-cycle flame temperature was found to be a more important factor for soot oxidation than the oxygen concentration, that is, air utilization. Accordingly, relatively high soot volume fractions were often found close to the cylinder axis in HSDI engines. ${ }^{22,40,42}$

Assuming that oxygen concentration and temperature distributions are similar in the previous ${ }^{40}$ and present engines, it can be concluded that the data in Figure 13 indicate that soot oxidation is improved with 


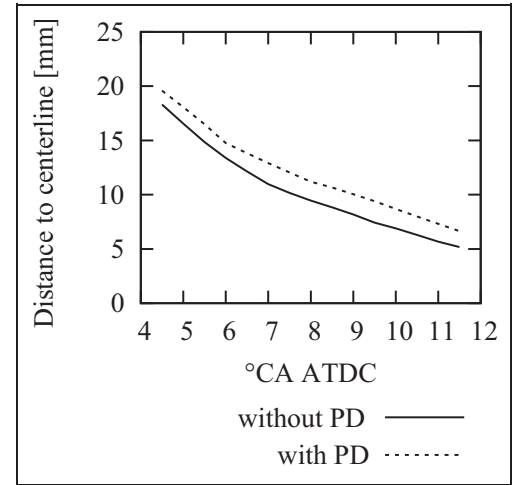

Figure 13. Averaged distance from the centerline of the combustion chamber to the rising edge of the soot signal for diesel fuel.

CA: crank angle; ATDC: after top dead center; PD: port deactivation.

PD, because mixing of the combustion gases with the relatively cold air close to the cylinder axis is reduced, due to slower propagation of the combusting sprays toward the center. Thus, reduced soot emissions at high-swirl conditions can be partly explained by the results depicted in Figure 13. In contrast, Figure 13 indicates that the reduced soot emissions with PD cannot readily be explained by air utilization, based on these data, because spray penetration decreases with increasing swirl.

\section{Variation in swirl for BLT}

The swirl effect on the combustion of BLT is described in the following. As noted in section "Ignition delay," the ignition delay is essentially independent of swirl for BLT. The corresponding $\mathrm{OH}^{*}$ images in the third and fourth columns of Figure 6 show that there is a certain azimuthal asymmetry in the early high-temperature combustion, that is, at $1.5^{\circ} \mathrm{CA}$ and $2.5^{\circ} \mathrm{CA}$, in particular with PD. However, Figure 6 also shows that the asymmetry decreases rapidly later in the cycle. Overall, the $\mathrm{OH}^{*}$ distributions are also very similar with and without PD.

Note also that the spatially integrated $\mathrm{OH}^{*}$ chemiluminescence in Figure 8(b) is essentially independent of swirl, and the corresponding COV is only slightly higher with PD for BLT. This is at first surprising because the corresponding ensemble-averaged data for diesel fuel in Figure 8(a) are significantly different with and without PD, as noted in section "Ensemble-averaged $\mathrm{OH}^{*}$ and soot images." Apparently, the fraction of pre-mixed combustion is not increased using PD for BLT, in contrast to diesel fuel. The overall weak influence of swirl on BLT combustion could be explained by the fact that pre-combustion mixing is strongly enhanced by the physical and/or chemical properties of this fuel, so that the swirl effect on pre-mixing is relatively small.

One might think that the enhanced pre-mixing was basically caused by the evaporation characteristics of BLT as compared to diesel fuel. Thus, additional tests are conducted with other alternative fuels, namely, ndecane and n-heptane, which have significantly different volatilities(the boiling temperatures of n-decane and n-heptane are $174{ }^{\circ} \mathrm{C}$ and $95{ }^{\circ} \mathrm{C}$, respectively ${ }^{5}$ ). The optical engine is operated on these single-component fuels at approximately the same operating conditions as for BLT and diesel fuel. ${ }^{5}$ Overall, the swirl effect on combustion turns out to be similar to the one observed for diesel fuel. The spatially integrated $\mathrm{OH}^{*}$ chemiluminescence for n-decane and n-heptane is shown in Figure 14(a) and (b), respectively, as an example. According to the discussion in section "Effect of swirl intensity on diesel fuel combustion," the fraction of pre-mixed combustion is obviously enhanced using PD for these two fuels because the $\mathrm{OH}^{*}$ intensities are relatively high with PD early in the stroke, that is, up to a CA of about $7^{\circ}$. Figures 8(a) and 14 also demonstrate that the fraction of pre-mixed combustion is increased for n-heptane as compared to both n-decane and diesel fuel. This can be basically explained by the high volatility of $n$ -

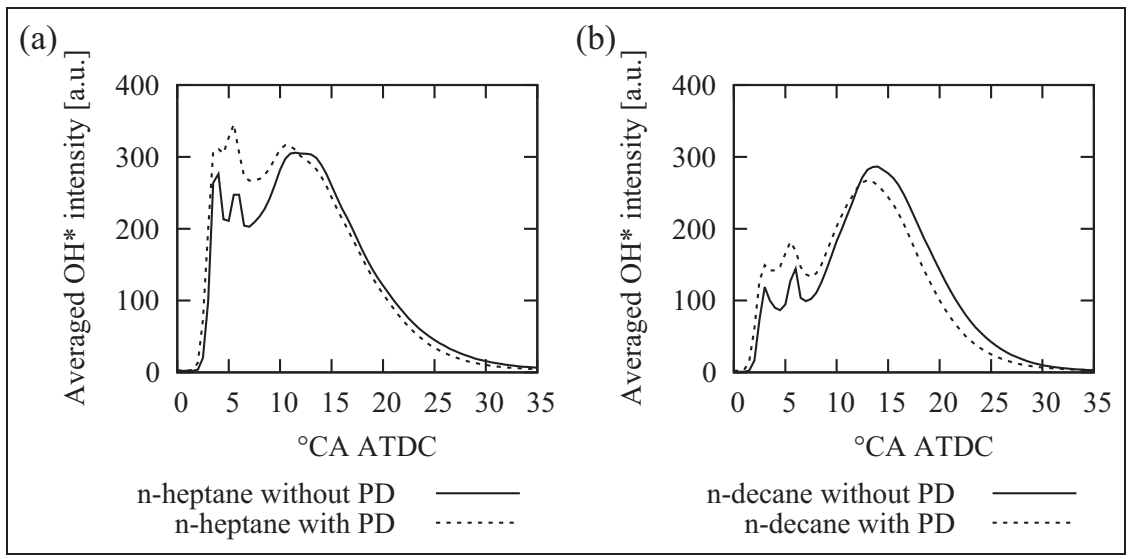

Figure 14. Spatially averaged $\mathrm{OH}^{*}$ chemiluminescence signal intensities for (a) n-heptane and (b) n-decane, as a function of degree CA. CA: crank angle; ATDC: after top dead center; PD: port deactivation. 
heptane. However, the fraction of pre-mixed combustion of n-heptane shown in Figure 14(b) is significantly smaller than the one observed for BLT in Figure 8(b). This indicates that the strongly enhanced pre-mixed combustion of BLT is basically not caused by its evaporation characteristics, but it is dominated by its long ignition delay, that is, the low fuel $\mathrm{CN}$ given in Table 2. Note that the $\mathrm{CN}$ is 78 and 54 , respectively, for $\mathrm{n}$ decane and $n$-heptane, so that the ignition delays are relatively short. $^{5}$

Both the weak influence of swirl on combustion and the vanishing soot emissions of BLT indicate that swirl could be reduced in future HSDI engines operating on BLT-like fuels. Recall that the reduction in soot emissions is a major reason for the application of swirlsupported systems. ${ }^{23}$

\section{Summary and conclusion}

Crude-oil independent, carbon-neutral liquid fuels are currently being developed for future HSDI engines due to the decreasing fossil-energy resources and global warming. In this work, a recently proposed, partly cellulose-derived, two-component fuel, denoted BLT, is investigated by optical high-speed combustion diagnostics, in order to support the mutual fuel and engine design process. The observed combustion characteristics of BLT are compared to the corresponding results of conventional diesel fuel and selected singlecomponent fuels, namely, n-heptane and n-decane. The experiments are conducted on an optically accessible engine and a comparable all-metal HSDI engine. In particular, the influence of in-cylinder air swirl is discussed in this article because this is an important design parameter. Major conclusions are summarized in the following:

1. The reduced $\mathrm{CN}$ of BLT leads to a long ignition delay, and therefore extensive pre-combustion mixing. Thus, the high-temperature combustion of BLT is relatively homogeneous and fuel lean. Consequently, soot formation is drastically reduced as compared to the reference fuels by both the tailored $\mathrm{CN}$ and fuel-bound oxygen of BLT.

2. The cyclic variability in high-temperature combustion is generally lower for BLT than for diesel fuel. In conclusion, cycle-by-cycle combustion variations appear to be dominated by the fuel $\mathrm{CN}$.

3. In contrast to the three reference fuels, the influence of swirl on BLT combustion in terms of both the ensemble-averaged quantities and the cycle-by-cycle variations is generally very weak. This could be basically explained by the reduced influence of swirl on pre-combustion mixing, which is apparently dominated by the long ignition delay of BLT. Consequently, the swirl level could be reduced in future HSDI engines for BLT-like fuels, as suggested also by the vanishing soot emissions even under low-swirl conditions.

4. The combustion of diesel fuel is significantly affected by air swirl as follows. Increases in swirl promote pre-combustion mixing, and therefore initial heat release and temperature. Thus, the LOL is reduced both globally and locally. However, this does not lead to enhanced soot formation (globally and locally) because the high-temperature reaction zone is substantially skewed with regard to the axis of each individual spray at high swirl. In addition, reduced soot formation may be caused by enhanced pre-combustion mixing upstream of the LOL at high swirl, as suggested previously. However, soot formation can hardly be predicted by previously proposed conceptual models of cylindrically symmetric diesel spray combustion under the current high-swirl conditions due to the observed strong asymmetry of the combusting jets. The role of the LOL is apparently less significant than previously thought because air entrainment into the jet core also occurs downstream of the LOL. In addition, increases in swirl likely promote soot oxidation because spray penetration and the resulting mixing of the combustion gases with the relatively cool air in the vicinity of the cylinder axis are reduced.

\section{Declaration of conflicting interests}

The author(s) declared no potential conflicts of interest with respect to the research, authorship, and/or publication of this article.

\section{Funding}

This work was performed as part of the Cluster of Excellence "Tailor-Made Fuels from Biomass," which is funded by the Excellence Initiative by the German federal and state governments to promote science and research at German universities.

\section{References}

1. Janssen A, Müther $\mathrm{M}$ and Pischinger S. Potential of cellulose-derived biofuels for soot free diesel combustion. SAE technical paper 2010-01-0335, 2010.

2. Mueller CJ, Pitz WJ, Pickett LM, Martin GC, Siebers DL and Westbrook CK. Effects of oxygenates on soot processes in DI diesel engines: experiments and numerical simulations. SAE technical paper 2003-01-1791, 2003.

3. Zannis TC, Hountalas DT, Papaglannakis RG and Levendis YA. Effect of fuel chemical structure and properties on diesel engine performance and pollutant emissions: review of the results of four European research programs. SAE technical paper 2008-01-0838, 2008.

4. Hottenbach P, Brands T, Grünefeld G, Janssen A, Müther M and Pischinger S. Optical and thermodynamic investigations of reference fuels for future combustion systems. SAE Int J Fuels Lubr 2010; 3(2): 819-838.

5. Jakob M, Hülser T, Janssen A, Adomeit P, Pischinger S and Grünefeld G. Simultaneous high-speed visualization 
of soot luminosity and $\mathrm{OH}^{*}$ chemiluminescence of alternative-fuel combustion in a HSDI diesel engine under realistic operating conditions. Combust Flame 2012; 159(7): 2516-2529.

6. Janssen A, Müther M, Pischinger S, Kolbeck A and Lamping M. Tailor-made fuels: the potential of oxygen content in fuels for advanced diesel combustion systems. SAE technical paper 2009-01-2765, 2009.

7. Westbrook CK. Biofuels combustion. Ann Rev Phys Chem 2013; 64: 201-219.

8. Idicheria CA and Pickett LM. Quantitative mixing measurements in a vaporizing diesel spray by Rayleigh imaging. SAE technical paper 2007-01-0647, 2007.

9. Siebers DL and Higgins BS. Flame lift-off on directinjection diesel sprays under quiescent conditions. SAE technical paper 2001-01-0530, 2001.

10. Chartier C, Aronsson U, Andersson Ö, Egnell R, Collin $\mathrm{R}$, Seyfried H, et al. Analysis of smokeless spray combustion in a heavy-duty diesel engine by combined simultaneous optical diagnostics. SAE technical paper 2009-011353, 2009.

11. Musculus MPB. Multiple simultaneous optical diagnostic imaging of early-injection low-temperature combustion in a heavy-duty diesel engine. SAE technical paper 2006-010079, 2006.

12. Pickett LM, Siebers DL and Idicheria CA. Relationship between ignition processes and the lift-off length of diesel fuel jets. SAE technical paper 2005-01-3843, 2005.

13. Pauls C, Grünefeld G, Vogel S and Peters N. Combined simulations and $\mathrm{OH}$-chemiluminescence measurements of the combustion process using different fuels under dieselengine like conditions. SAE technical paper 2007-010020, 2007.

14. Musculus MPB. Effects of the in-cylinder environment on diffusion flame lift-off in a DI diesel engine. SAE technical paper 2003-01-0074, 2003.

15. Pickett LM and Lopez JJ. Jet-wall interaction effects on diesel combustion and soot formation. SAE technical paper 2005-01-0921, 2005.

16. Aronsson U, Richter M, Andersson O, Sjöholm J, Chartier C, Alden M and Egnell R. Analysis of the correlation between engine-out particulates and local equivalence ratio in the lift-off region of a heavy duty diesel engine using Raman spectroscopy. SAE technical paper 200901-1357, 2009.

17. Adolph D, Rezaei R, Pischinger S, Adomeit P, Körfer T, Kolbeck A, et al. Gas exchange optimization and the impact on emission reduction for HSDI diesel engines. SAE technical paper 2009-01-0653, 2009.

18. Adomeit P, Pischinger S, Becker M, Rohs H, Greis AE and Grünefeld $\mathrm{G}$. Potential of soot and $\mathrm{CO}$ reduction for HSDI diesel combustion systems. SAE technical paper 2006-01-1417, 2006.

19. Donkerbroek AJ, Boot MD, Luijten CCM, Dam NJ and ter Meulen JJ. Flame lift-off length and soot production of oxygenated fuels in relation with ignition delay in a DI heavy-duty diesel engine. Combust Flame 2010; 158(3): 525-538.

20. Persson H, Andersson Ö and Egnell R. Fuel effects on flame lift-off under diesel conditions. Combust Flame 2010; 158(1): 91-97.

21. Taschek M, Koch P, Egermann A and Leipertz A. Simultaneous optical diagnostics of HSDI diesel combustion processes. SAE technical paper 2005-01-3845, 2005.
22. Hildingsson L, Johansson B, Hultqvist A, Särner G, Richter $M$ and Alden M. Simultaneous formaldehyde and fuel-tracer LIF imaging in a high-speed diesel engine with optically accessible realistic combustion chamber. SAE technical paper 2005-24-008, 2005.

23. Miles PC. The influence of swirl on HSDI diesel combustion at moderate speed and load. SAE technical paper 2000-01-1829, 2000.

24. Koyanagi K, Öing H, Renner G and Maly R. Optimizing common rail-injection by optical diagnostics in a transparent production type diesel engine. SAE technical paper 1999-01-3646, 1999.

25. Dec JE. A conceptual model of DI diesel combustion based on laser-sheet imaging. SAE Trans 1997; 106(3): $1319-1348$.

26. Bruneaux G. Detailed analysis of mixture and combustion of diesel jets by laser induced fluorescence techniques. In: 7th international symposium: towards clean diesel engines (ed C Schulz and N Peters), Aachen, 4-5 June 2009, ISSN 1613-0073, Vol. 452, CEUR proceedings, http://ceur-ws.org/Vol-452/

27. Singh S, Reitz RD, Musculus MPB and Lachaux $T$. Simultaneous optical diagnostic imaging of lowtemperature, double-injection combustion in a heavyduty DI diesel engine. Combust Sci Tech 2007; 179: 23812414.

28. Bruneaux G. Combustion structure of free and wallimpinging diesel jets by simultaneous laser-induced fluorescence of formaldehyde, poly-aromatic hydrocarbons, and hydroxides. Int J Eng Res 2008; 9(3): 249-265.

29. Kosaka H, Aizawa $\mathrm{T}$ and Kamimoto T. Two-dimensional imaging of ignition and soot formation processes in a diesel flame. Int $J$ Eng Res 2005; 6: 21-42.

30. Kojima J, Ikeda Y and Nakajima T. Spatially resolved measurement of $\mathrm{OH}^{*}, \mathrm{CH}^{*}$, and $\mathrm{C}^{*}$ chemiluminescence in the reaction zone of laminar methane/air premixed flames. Proc Combust Inst 2000; 28: 1757-1767.

31. Cardenas M, Hottenbach P, Kneer R and Grünefeld G. Investigations of clustered diesel jets under quiescent high-pressure and high-temperature conditions using Mie, Schlieren, and chemiluminescence imaging. SAE Int $J$ Eng 2010; 2(2): 272-286.

32. Mueller CJ and Martin GC. Effects of oxygenated compounds on combustion and soot evolution in a DI diesel engine: broadband natural luminosity imaging. SAE technical paper 2002-01-1631, 2002.

33. Shiozaki T, Nakajima $\mathrm{H}$, Yokota $\mathrm{H}$ and Miyashita A. The visualization and its analysis of combustion flame in a DI diesel engine. SAE technical paper 980141, 1998.

34. Gauding M, Brands T, Felsch C, Hottenbach P, Hasse C, Pauls $\mathrm{C}$, et al. Experimental and numerical investigation of ignition mechanisms for multiple injection strategies at diesel engine-like conditions. In: European combustion meeting, Vienna University of Technology, Vienna, Austria, 14-17 April 2009.

35. Müther M, Lamping A, Kolbeck M, Cracknell RF, Rickeard DJ, Ariztegui J and Rose KD. Advanced combustion for low emissions and high efficiency, part 1: impact of engine hardware on HCCI combustion. SAE technical paper 2008-01-2405, 2008.

36. Aronsson U, Chartier C, Horn U, Andersson Ö, Johansson B and Egnell R. Heat release comparison between optical and all-metal HSDI diesel engines. SAE technical paper 2008-01-1062, 2008. 
37. Kook S and Pickett LM. Effect of fuel volatility and ignition quality on combustion and soot formation at fixed premixing conditions. SAE technical paper 2009-01-2643, 2009.

38. Colban WF, Kim D, Miles PC, Oh S, Opat R, Krieger R, et al. A detailed comparison of emissions and combustion performance between optical and metal single-cylinder diesel engines at low temperature combustion conditions. SAE technical paper 2008-01-1066, 2008.

39. Kashdan JT and Thirouard B. A comparison of combustion and emissions behaviour in optical and metal singlecylinder diesel engines. SAE Int J Eng 2009; 2(1): $1857-$ 1872.

40. Greis AE. Laseroptische Untersuchungen des Verbrennungsprozesses in einem PKW-Dieselmotor. PhD Thesis, RWTH Aachen University, Aachen, 2007.

41. Zhao H and Ladommatos N. Engine combustion instrumentation and diagnostics. Warrendale, PA: Society of Automotive Engineers, Inc., 2001.

42. Adolph D, Deutscher $\mathrm{M}$ and Felsch C. $\mathrm{CO}_{2}$-optimierter, rußfreier Dieselmotor. BMWi project final report. Förderkennzeichen 19U4020A, 6 August 2010. doi: 10.2314/ GBV:634008692.

43. Siebers DL. Liquid-phase fuel penetration in diesel sprays. SAE technical paper 980809, 1998.

44. Siebers DL. Scaling liquid-phase fuel penetration in diesel sprays based on mixing-limited vaporization. SAE technical paper 1999-01-0528, 1999.

45. Kosaka H, Nishigaki T, Kamimoto T, Sano T, Matsutani A and Harada S. Simultaneous 2-D imaging of $\mathrm{OH}$ radicals and soot in a diesel flame by laser sheet techniques. SAE technical paper 960834, 1996.

46. Heywood J. Internal combustion engines fundamentals. New York: McGraw-Hill, 1988.

47. Tippelmann G. A new method of investigation of swirl ports. SAE technical paper 770404, 1977.

48. Tree DR and Dec JE. Extinction measurements of incylinder soot deposition in a heavy-duty DI diesel engine. SAE technical paper 2001-01-1296, 2001.

49. Van Gerpen JH, Huang C-W and Borman GL. The effects of swirl and injection parameters on diesel combustion and heat transfer. SAE technical paper 850265 , 1985.

50. Winterbone DE, Yates DA, Clough E, Rao KK, Gomes $\mathrm{P}$ and Sun J-H. Combustion in high-speed direct injection diesel engines - a comprehensive study. Proc IMechE, Part C: J Mechanical Engineering Science 1994; 208: 223 240.

51. Pickett LM and Siebers DL. Soot formation in diesel fuel jets near the lift-off length. Int J Engine Res 2006; 7: 103 130.

52. Bergstrand P and Denbratt I. Diesel combustion with reduced nozzle orifice diameter. SAE technical paper 2001-01-2010, 2001.

53. Higgins BS and Siebers DL. Measurement of the flame lift-off location on DI diesel sprays using $\mathrm{OH}$ chemiluminescence. SAE technical paper 2001-01-0918, 2001.

\section{Appendix I}

\section{Flow tagging}

The applied high-speed visualization of the combustion process yields information on the in-cylinder flow field, provided that the effects of flow and chemistry/ temperature can be separated. Such a situation is given during the volumetric combustion of the diesel fuel distribution trails after the end of injection, which was described in the section Ensemble-averaged $\mathrm{OH}^{*}$ and soot images and in Jakob et al. ${ }^{5}$ The acquired $\mathrm{OH}^{*}$ images indicate that approximately the entire combusting fuel distributions are visualized at a crank angle (CA) of about $5.5^{\circ}$ after top dead center (ATDC) because sufficient time elapsed since the end of injection for evaporation and auto-ignition to occur in almost the entire fuel distribution trails (except in very lean regions at the periphery). The corresponding, ensemble-averaged $\mathrm{OH}^{*}$ images of the measurements presented in Figure 6 are displayed in Figure 9(a) and (b). They show that the combusting fuel distribution trails are clearly recognized between the nozzle tip and a radial distance of about $12 \mathrm{~mm}$. Beyond this radial distance, the combusting fuel distributions of the individual sprays are generally not recognized because spray-wall impingement leads to enhanced turbulent mixing in this region. However, the $\mathrm{OH}^{*}$ images at 4.5 ${ }^{\circ} \mathrm{CA}$ and $5.5^{\circ} \mathrm{CA}$ in Figures 6 and 9, respectively, indicate that the clockwise swirl velocity is significantly increased there because a fraction of the spray momentum is deflected in this direction.

The flow velocity can be determined more accurately in the inner portion of the field of view, which is hardly disturbed by wall impingement. It can be assumed that the visualized fuel in this region emanated from the nozzle at the end of the (regular) injection event because the velocity of the combusting fuel distribution trails in the radial direction is obviously low there. Note that a very low injection velocity and a strong deceleration of the spray occur only at the end of injection. Hence, the swirling flow is tagged at the end of injection. Thus, the $\mathrm{OH}^{*}$ distributions in Figure 9 essentially show the swirl-induced displacement of the reacting fuel distribution trails in the inner region since the end of injection. In order to illustrate this effect, the spray centerlines are also displayed in Figure 9 (the current and previous ${ }^{21,24}$ Mie scattering measurements, for example, in Figure 6, demonstrate that the liquid fuel sprays are hardly deflected by the charge motion in the inner region, so that they are assumed to be straight in Figure 9). These images clearly show the effect of the air swirl. The observed combusting fuel distribution trails, which are approximately straight in the inner region, demonstrate that the flow field is similar to solid-body rotation in the vicinity of each individual spray. However, a certain azimuthal asymmetry in the flow is found because the displacement of the individual reacting fuel distribution trails is noticeably different.

The absolute uncertainty in this measurement arises basically from the error of the determination of the end of injection, which is $0.5^{\circ}$, corresponding to $25 \%$. However, the precision of this measurement is significantly better because the end of injection is approximately equal for all individual fuel jets. Overall, the relative uncertainty is estimated to be about $10 \%$. 
The described flow measurement is essentially not affected by soot-OH* cross-talk because soot luminosity is negligible in the investigated inner portion of the field of view at $3.5^{\circ} \mathrm{CA}-5.5^{\circ} \mathrm{CA}$, as shown in Figure 7 . The extension of the sooting region is also quantified below. In addition, Figure 7 illustrates that the concerning soot signal in the inner region, which is basically caused by surface-scattered luminosity, is smooth, so that the exploited distinct structure of the $\mathrm{OH}^{*}$ images is hardly affected.

\section{Appendix 2}

\section{Lift-off length determination and cyclic variability in lift-off length}

The method to determine the lift-off length (LOL) is similar to the procedure described in Pauls et al. ${ }^{13}$ However, due to in-cylinder swirl, the flame is asymmetric to the spray axis. Instead of using a weighted profile, an unweighted normalized profile with a threshold (approximately 25\% of the individual maximum) leads to a precise determination of the LOL. Considering only the relevant area of the flame around the spray axis, the method can be applied to each one of the eight fuel sprays. To take window fouling into account, the $\mathrm{OH}^{*}$ signal intensity of each individual spray is normalized to its maximum. Note that the determination of the LOL is hardly affected by optical soot-OH* cross-talk, basically because significant luminosity signals do not occur at the LOL in the interesting CA range up to $6{ }^{\circ} \mathrm{CA}$ ATDC. This is demonstrated in more detail above. The LOL measurement may be slightly affected by the normalization of the exploited axial $\mathrm{OH}^{*}$ profiles, ${ }^{5,13}$ in which $\mathrm{OH}^{*}$ intensities downstream of the LOL are taken into account. However, the soot luminosity traces in Figure 8(c) indicate that the interfering signals are both relatively low and approximately equal with and without port deactivation (PD) in the concerning phase up to $6{ }^{\circ} \mathrm{CA}$ ATDC. Thus, this effect is expected to be negligible in the discussion of the variation in swirl intensity.

The coefficients of variation (COVs) in Figure 11(c) and (d) show that there are essentially three different phases. First, particularly high cyclic variations are observed early in the cycle. Accordingly, it was demonstrated previously that there were relatively strong fluctuations of the LOL shortly after ignition by measurements in a constant-volume vessel. ${ }^{4}$ However,
Figure 11(c) and (d) show that the first phase ends at about $3{ }^{\circ} \mathrm{CA}$ without $\mathrm{PD}$ and at about $2.5{ }^{\circ} \mathrm{CA}$ with $\mathrm{PD}$, respectively. Note that the ignition probability of all the individual sprays (not shown) has just reached $100 \%$ at these CAs.

Although the cyclic variability is relatively low in the second phase, it is generally higher than the one observed for (approximately) quasi-steady diesel sprays in vessels. The latter was consistently found to be about $7 \%$ for comparable sprays in Cardenas et al. ${ }^{31}$ and Higgins and Siebers. ${ }^{53}$

The relatively high COV observed in the second phase of the present data essentially cannot be explained by the early end of injection. Note that similar, relatively high cyclic fluctuations of the LOL were also found for long injection durations, that is, quasisteady combustion, in a heavy-duty engine. ${ }^{14}$ Thus, the high LOL fluctuations in engines are basically caused by the ambient conditions, which are different in vessels ${ }^{5}$ and references therein. In particular, the high $\mathrm{COV}$ of the LOL in engines is likely caused by flow effects and temperature variations. Accordingly, Figure 11(c) and (d) demonstrate that the COV is generally increased with PD. Variations in the ambient air temperature may also lead to higher fluctuations of the LOL, because the temperature field is inhomogeneous in engines, and a particularly strong link between temperature and the LOL was found previously. According to Musculus ${ }^{14}$ and Siebers and Higgins, ${ }^{9}$ the quasisteady LOL was observed to be proportional to $\mathrm{T}^{-3.3}$ in an engine and to $\mathrm{T}^{-3.7}$ in a vessel.

Finally, Figure 11(c) and (d) show that the COV of the LOL increases significantly after a CA of about $4.5^{\circ}$ ATDC. This is caused by the volumetric ignition and combustion process in the vapor trails of the sprays, which is discussed in section "Ensemble-averaged $\mathrm{OH}^{*}$ and soot images" and in Jakob et al. ${ }^{5}$ Figure 11(a) and (b) illustrate that this process leads to very low LOLs late in the cycle due to the low radial velocity of the flow. ${ }^{5}$ Note that the LOL measurements in phase \#2 are particularly reliable due to the relatively low cycleby-cycle variability in this phase shown in Figure 11(c) and (d). Relatively high cyclic LOL variations in sprays \#1 and \#8, which are observed for both operating conditions in the second phase of pre-mixed combustion shown in Figure 11(c) and (d), could be essentially caused by the proximity to the exhaust valves. 